Est Ag 36 (2001) 461-494

\title{
La misión de Pablo y sus enemigos en Corinto
}

Pablo fue un hombre conflictivo tanto por su carácter personal como por su mensaje. Desde el comienzo de su misión independiente, a raíz del conflicto de Antioquía, pronto le surgieron enemigos ad extra y ad intra de la comunidad en los grandes centros donde el Apóstol predicó el evangelio y fundó comunidades. Así vemos que Pablo tuvo que hacer frente a una misión antipaulina encabezada por los judaístas cristianos en Galacia y en Filipos. Éstos exigían la circuncisión y otros requisitos de las leyes judías a neocristianos provenientes del mundo pagano. Pablo hace frente a la incursión de estos enemigos con sus cartas dirigidas a dichas comunidades e intenta defender en sus comunidades su evangelio de libertad frente a la ley ${ }^{1}$. Si leemos detenidamente las cartas a los Corintios, también vemos que el apóstol tuvo conflictos internos, que en parte motivaron la correspondencia paulina con los corintios. En este artículo intentaré exponer el status questionis sobre un tema tan discutido, como es la identificación de los enemigos paulinos en Corinto. Todo el problema estriba en que las fuentes no son precisas, como posteriormente veremos. No estamos ante un "problema policial", por lo que tampoco haremos de Sherlock Holmes.

\section{1.- La misión de Pablo en Corinto}

La ciudad portuaria de Corinto, sede de la provincia romana de Acaya, era en la época paulina un centro comercial, donde se mezclaban distintos pueblos, religiones ${ }^{2}$, filosofías y culturas. Este ambiente tolerante y multirre-

1. Para un estudio de los enemigos cristianos paulinos en Galacia y Filipos, así como las motivacioónes políticas y religiosas de la misión antipaulina, véase mi tesis, Die Religionspolitik des Kaisers Claudius und die paulinische Mission (HBS 19), Herder, Freiburg 1999, 291-340.

2. Sobre las distintas religiones extranjeras, misterios y cultos en Corinto cfr. $O$. Bronner, Paul and the Pagan Cults at Isthmia, in: HThR 64 (1971) 169-187; H. Conzelmann, Korinth und die Mädchen der Aphrodite, in: idem, Theologie als Schriftauslegung. Aufsätze zam Neuen Testament (BEvTh 65), München 1974, 152-166; H.-J. Klauck, Herrenmahl und 
ligioso fue positivo para la expansión del cristianismo, sin embargo trajo también consigo el peligro del sincretismo. Esta sociedad multicultural con distintas filosofías y religiones influyó sin lugar a dudas en la forma de entender el cristianismo entre los cristianos procedentes del paganismo, de modo que dentro de la misma comunidad cristiana se defendían distintos puntos de vista y existían distintas concepciones religiosas.

La comunidad de Corinto creció rápidamente. Sus miembros eran en su mayoría cristianos de origen pagano (1 Cor 12,23) y conservaban prácticas de su pasado religioso gentil. Muchos de los problemas o malentendidos (p.e. participación en banquetes sacrificiales paganos, relaciones con heteras...) ante los cuales Pablo tomó postura, se explican perfectamente teniendo en cuenta el pasado pagano. Otro grupo, aunque reducido, lo constituían los judeocristianos: Áquila y Priscila, Crespo (1 Cor 1,14; Hech 18,8), Apolo (Hech 18,24f.; 1 Cor 16,12;1,12s.) y tal vez Sóstenes 4 (1 Cor 1,1). Sólo presuponiendo la existencia de judeocristianos, se puede explicar que Pablo se dirija a los creyentes circuncisos en Corinto $(1$ Cor 7,18$)$ y apele a la ley mosaica (1 Cor 9,8-10;14,34). La existencia de un grupo judío en la ciudad de Corinto a mediados del s. I está corroborada por algunos documentos literarios, como Filón de Alejandría (LegGai 281s.) y Hech 18,4,y posiblemente mediante una inscripción 5 . En la comunidad también había "temerosos de Dios", p.e. Ticio Justo, y posiblemente Estéfanas. Resumiendo, podemos decir que obtenemos un cuadro de una comunidad compuesta de circuncisos e incircuncisos, por cual los textos 1 Cor 1,22-24 y 9,20-22 pudieran aludir perfectamente a una audiencia mixta en Corinto.

hellenistischer Kult. Eine religionsgeschichtliche Untersuchung zum ersten Korintherbrief (NTA.NF 15), Münster 1982; J. Murphy-O'Connor, St. Paul's Corinth: Texts and Archology, Wilmington 1983,3-44. Una amplia bibliografía sobre Corinto y S. Pablo la encontramos en Ben Witherington III, Conflict \& Community in Corinth. A Socio-Rethorical Commentary on 1 and 2 Corinthians, Eerdmans - Paternoster Press, Grand Rapids - Carlisle 1994, 48-67.

3. Una nueva interpretación de este difícil versículo nos la ofrece $T$. Paige, 1 Corinthians 12.2: A Pagan Pompe?, in: JSNT 44 (1991) 57-65. El texto se entiende en la exégesis moderna en relación a experiencias extáticas dentro de los cultos paganos, en los cuales los cristianos también participaban. Este autor propone que el estilo (lenguaje) y la imagen del pasaje se ha de entender como una referencia a la participación en una procesión religiosa, la pompe (p. 65).

4. Es dudoso si este personaje se puede identificar con el el jefe de la sinagoga de Corinto (Hech 18,17).

5. La inscripción sinagogal $\sigma v v \alpha] \gamma \omega \gamma \eta \mathrm{E} \beta[\alpha 1 \omega v$ (J.H. Kent, Corinth. Results of excavations conducted by the American School of Classical Studies at Athens, Bd. VIII, 1 nr. 111), es más tardía, cfr. H.-J. Klauck, Herrenmahl 234, n. 3. 
Desde las publicaciones de $G$. Theißen 6 referentes a la comunidad de Corinto, la atención de los exégetas modernos ${ }^{7}$ se ha centrado preferentemente en las estructuras sociales y en el rango social de los miembros de la comunidad. $G$. Theißen menciona cuatro criterios para inferir el status social elevado de algunos cristianos de Corinto: a) la mención de cargos públicos, b) la posesión de casas, c) la mención de servicios de dirección y d) la mención de viajes. En esta comunidad, compuesta de gente proveniente de distintas clases sociales (artesanos, asalariados y esclavos), había también según 1 Cor 1,26 gente acomodada 8 , aunque eran los menos. De las afirmaciones paulinas en 1,26-29 y 11,17-22 se debe concluir que la comunidad cristiana en Corinto no sólo estaba compuesta de artesanos libres y pequeños comerciantes, sino que la mayoría de sus miembros no tenían ni prestigio social ni propiedades. En todo caso, hay que resaltar que las diferencias sociales dentro de la comunidad eran muy importantes. Algunos de los problemas de la vida comunitaria de la comunidad, los cuales Pablo intenta solucionar en 1 Cor, tienen su origen en estas diferencias sociales: La cuestión de la cena del Señor (1 Cor $11,17 \mathrm{ss})^{9}$ proviene de la tensión entre cristianos ricos y pobres, así como tam-

6. G. Theißen, Estudios de sociología del cristianismo primitivo (BEB 51), Sígueme, Salamanca 1985,193-217; idem., Vers une theorie de l'histoire sociale du christianisme primitif, in: ETR 63 (1988) 210ss.

7. Entre tantos estudios hay que mencionar los siguientes: A.D. Clarke, Secular and Christian Leadership in Corinth. A Socio-Historical and Exegetical Study of 1 Corinthians 1-6 (AGJU 18), Leiden 1993; T. Engberg- Pedersen, The Gospel and Social Practice according to 1 Corinthians, in: NTS 33 (1987) 557-584; E. Sch. Fiorenza, Rethorical Situation and Historical Reconstruction in 1 Corinthians, in: NTS 33 (1987) 386-406; E.A. Judge, Christliche Gruppen in nichtchristlicher Gesellschaft. Die Sozialstruktur christlicher Gruppen im ersten Jahrhundert (Neue Studienreihe 4), Wuppertal 1964; H.-J. Klauck, Gemeindestrukturen im ersten Korintherbrief, in: BiKi 40 (1985) 9-15; P. Marshall, Enmity in Corinth. A Social Conventions in Paul's Relations with the Corinthians (WUNT 2. Reihe 23), Tübingen 1987; W.A. Meeks, Los primeros cristianos urbanos. El mundo social del apóstol Pablo (BEB 64), Salamanca 1988; L. Schottroff, "Nicht viele Mächtige". Annäherung an eine Soziologie des Urchristentums, in: BiKi 40 (1985) 2-8. A. Rakotoharintsifa, Conflits à Corinthe. Église et societé selon I Corinthiens. Analyse socio-historique (MoBi 36), Genève 1997.

8. Cabría mencionar Erastos, funcionario de finanzas de la ciudad (Rom 16,23). Una inscripción latina encontrada en Corinto testifica la existencia de un cierto Erastos como edil de la ciudad en torno a los años 50, cfr. J.H. Kent, Corinth, Bd. VIII, 3, nr. 232; G. Theißen, Estudios 216, identifica el Erastos de la inscripción con el mencionado en Rom 16,23. Sobre este personaje véase H.J. Cadbury, Erastus of Corinth, en: JBL 50 (1931) 4258; A.D. Clarke, Leadership 46-56.

9. H.-J. Klauck, Herrenmahl und hellenistischer Kult. Eine religion geschichtliche Untersuchung zum ersten Korintherbrief (NTA.NF 15), 2. Aufl., Münster 1982, 235-374; W.A. Meeks, Los primeros cristianos 120 s.170s. 
bién por el hecho de entender la "Cena del Señor" como un banquete helenista, en el que se demostraban las diferencias sociales. Del mismo modo, la educación de los miembros (los "conocedores" y los débiles en el cap. 8) jugó un papel importante en el funcionamiento de la comunidad. Por tanto, el problema de la tensión social interna tenía para Pablo también una dimensión teológica.

Algunos autores, como veremos posteriormente, han investigado el trasfondo histórico-religioso de la comunidad de Corinto. W. Schmithals propuso la tesis de que en Corinto existió una corriente gnóstica precristiana, con la cual Pablo polemizó en sus cartas. Según el apóstol, esta corriente defendería un dualismo metafísico, un mito salvador no cristiano, una ascesis radical y la degradación de la carne (cuerpo). Pero el texto de 1 Cor no indica que Pablo tuviera que enfrentarse en Corinto con el problema gnóstico y por eso dicha tesis ha sido muy criticada. Otros influjos más claros para la presentación del cristianismo en Corinto provienen del judaísmo: la heredad del A.T. y de la apocalíptica judía, así como la especulación sobre la Sabiduría de las sinagogas de la diáspora judía, la cual también se encuentra en los libros de la Sab, Sir y en Filón de Alejandría. Así mismo, se encuentran y se reconocen huellas de la filosofía cínica-estoica (1 Cor 6,$12 ; 10,23)^{10}$.

Pero no sólo las ideas de la filosofía popular encontraron eco y admiración dentro de la comunidad cristiana, sino que a ello hay que unir para la presentación multiforme del cristianismo el hecho de que los misioneros cristianos, que actuaron en Corinto, no tenían una línea homogénea.

Este trasfondo social, religioso y filosófico de la variopinta comunidad de Corinto llevó a mal interpretar el mensaje cristiano predicado por Pablo en su visita fundacional. Después de su comparecencia ante el procónsul Galión (Hech 18,12-17), Pablo, Áquila y Priscila abandonaron la ciudad de Corinto en torno al año 52 d.C., y se fueron a Éfeso, donde se encontraron con Apolo (Hech 18,24-19,1). Éste se marchó a Corinto y predicó allí con éxito en ausencia de Pablo. El apóstol seguía estando en contacto con su comunidad, a la que consideraba como su campo privado, bien mediante intercambio de información oral $(1$ Cor 1,$11 ; 5,1 ; 11,18)$ o por intercambio de cartas. Mediante este contacto ininterrumpido obtuvo información sobre el desarrollo y evolución de la fe en Corinto, así como de las dificultades y divisiones que surgieron después de haber abandonado la comunidad. Pablo tuvo que afrontar la situación y precisar sus primeras afirmaciones. Además, esta comunidad le

10. Cfr. F.G. Downing, Cynics, Paul and the Pauline Churches. Cynics and Christian Origins II, London - New York 1998. 
plantea cuestiones por escrito referentes a la praxis y actitud de los cristianos (1 Cor 7,1). El apóstol reacciona ante problemas precisos de la comunidad. Fruto de este contacto son las "dos cartas canónicas" que conservamos. Son una respuesta ocasional y ad hoc a la situación que se había originado en la iglesia de Corinto. La situación, sin embargo, no es descrita, dado que Pablo y sus interlocutores ya la conocen. No obstante, se puede en parte inferir y reconstruir el sistema de relaciones intraeclesiales en Corinto partiendo de algunas afirmaciones y críticas del apóstol.

Dos temas han sido analizados por los estudiosos en este campo. El primero trata de las relaciones existentes dentro de la comunidad de Corinto, y el segundo sería la relación entre Pablo y los Corintios. Aunque ciertamente las divisiones entre la misma comunidad son preocupantes, la forma más grave de división para el Apóstol es la que hay entre la mayoría de los miembros de la comunidad y Pablo mismo. Se le oponen en casi todos los temas y ponen en tela de juicio su autoridad de apóstol. Las relaciones en el interior de la comunidad se ha denominado como la problemática de los "partidos" en la comunidad. Intentaremos identificar a los personajes que produjeron esta tensión dentro de la comunidad. Analizaremos la información existente para dilucidar si se puede llegar a alguna conclusión, o más bien hay que dejar la cuestión en el aire por falta de datos.

\section{La primera carta a los Corintios y la división de la comunidad}

El primer problema con el que se enfrentan los exégetas que analizan 1 Cor es la falta de un principio de composición formal, es decir, la primera carta a los Corintios no constituye un documento literario unitario ${ }^{11}$. Esta corriente de investigación constata tensiones literarias en la carta, las cuales

11. J. Weiss, Der erste Korintherbrief. Zweiter Neudruck der völlig neubearbeiteten Auflage 1910 (KEK 5), Göttigen 1970, es uno de los primeros estudiosos que aplicó la crítica de las fuentes y la crítica literaria a esta carta. W. Schmithals, Ch. Senft, H.-J. Klauck y $R$. Pesch pueden considerarse como exponentes de esta tradición interpretativa. Sobre el problema de la crítica literaria de 1 Cor cfr. H. Merklein, Der erste Brief an die Korinther. Kapitel 1-4 (ÖTKNT 7/1), Gütersloh - Würzburg 1992, $42-50$ (amplia literatura al respecto p. 42s.); W. Schrage, Der erste Brief an die Korinther. 1. Teil: 1 Kor 1,1-6,11 (EKK VII 1), Zürich - Neukirchen-Vluyn 1991, 63-71. Un visión panorámica de las distintas hipótesis sobre la composición y división de la carta la encontramos en G. Sellin, Hauptprobleme des Ersten Korintherbriefes, in: ANRW II 25.4 (1987) 2940-3044, aquí 2965-2968. M. de Burgos Núñez, La Correspondencia de Pablo con las Comunidades de Corinto, in: Communio 26 (1993) 42-53, nos ofrece también un resumen sobre la unidad de la carta. 
interpreta como rupturas textuales. De ahí concluye la falta de unidad literaria. Por el contrario, otra corriente de investigación exegética ${ }^{12}$ considera la carta como una unidad literaria y teológica. Según esta línea de interpretación, las tensiones en la composición retórica de un texto pudieran ser resultado de un cambio de perspectiva en la presentación de los hechos. De todos modos, éste no es nuestro tema, por lo que no profundizaremos en él.

La ciudad de Éfeso es comúnmente aceptada como lugar de composición de las cartas dirigidas a Corinto (1 Cor 16,8; 15,32). Sabemos que Pablo estuvo tres años (Hech 19,8-10) en dicha ciudad después de haber abandonado Corinto. Se presupone su datación entre los años 51-54 o 52-55. Discutido es si Pablo las escribió al principio o al final de su estancia en Éfeso ${ }^{13}$.

La evolución de la comunidad cristiana de Corinto nos la explica $A$. Schreiber en su monografía ${ }^{14}$ aplicando un modelo que tiene en cuenta aspectos sociales y psicológicos dentro del grupo. Según este estudioso, al principio, cuando Pablo estaba presente todavía en la comunidad, no existía ninguna división entre los creyentes: los cristianos constituían un pequeño grupo unido entorno a un único dirigente reconocido. Este reconocimiento se basaba en una experiencia espiritual intensa. Pero cuando Pablo abandonó la comunidad, surgió un proceso natural de diferenciación de los roles y aparecieron divisiones dentro de la comunidad cristiana, y algunos cuestionaron la autoridad de Pablo.

12. Representantes de esta tendencia son entre otros: H. von Soden, G. Bornkamm, $H$. Conzelmann, Chr. Wolff, H. Merklein y F. Lang. Llama la atención que la exégesis americana considera 1 Cor como una unidad literaria y postula una interpretación sincrónica de la carta.

13. Según W. Schrage, 1 Kor 36; H. Merklein, 1 Kor 51, Pablo la escribiría a principios del año 54 o 55; H. Conzelmann, Der erste Brief an die Korinther (KEK V), 2. Aufl., Göttingen 1981, 16, n. 31 y R. Jewett, Paulus-Chronologie. Ein Versuch, München 1982, 41.162: principios del 55; N. Hyldahl, Die paulinische Chronologie (AThD 19), Leiden 1986, 115.122: Abril 54. A. Suhl, Paulus und seine Briefe. Ein Beitrag zur paulinischen Chronologie (StNT 11), Gütersloh 1975, año 53. G. Sellin, "Hauptprobleme" 2993ss., data incluso las distintas cartas incluidas en 1 Cor: Cor A (principios del 52); Cor B antes de Pentecostés 52; Cor C o 1 Cor 1-4 (otoño 52); Cor D o Apología (principios del 53); Cor E o Carta de las lágrimas (verano 53); Cor F o carta de reconciliación (principios del 54); 2 Cor 9 (antes del verano 54). S. Vidal, Las cartas originales de Pablo (Colección Estructuras y Procesos. Serie Religión), Valladolid 1996, 119-281: Cor A (otoño 52), Cor B (primavera 53); Cor C (verano 53); Cor D (otoño 53). Una excepción para la datación de 1 Cor en este periodo de tiempo la constituye G. Lüdemann, Paulus, der Heidenapostel I: Studien zur Chronologie (FRLANT 123), Göttingen 1980, 273: año 49.

14. A. Schreiber, Die Gemeinde in Korinth. Versuch einer gruppendynamischen Betrachtung der Entwicklung der Gemeinde von Korinth auf der Basis des ersten Korintherbriefes (NTA.NF 12), Münster 1977. 
La oposición a Pablo era múltiple y por diversos motivos. Algunos enemigos criticaron duramente al Apóstol y afirmaban que éste tenía miedo. Según ellos, Pablo no se atrevía a regresar a Corinto y por eso enviaba a Timoteo $(4,6.18)$. Su renuncia al derecho del misionero de vivir a costa de la comunidad fue interpretado como una falta de autoconciencia apostólica (cap. 9). Otra discusión se centraba en torno a la escatología: había cristianos que rechazaban la resurrección de los muertos (cap. 15).

Pablo también habla de discordias en 1 Cor 11,17-34. Ellas eran consecuencia de la confrontación social entre dos grupos cristianos: los ricos y los pobres. Dicha división era patente cuando la comunidad local se reunía para celebrar la cena del Señor. La situación descrita es la siguiente: En la celebración de la Cena del Señor, los ricos traían de sus casas su propia comida y comenzaban a comer antes de que se reuniera toda la comunidad. Los esclavos y los trabajadores que no podían abandonar la casa de su señor o el trabajo antes de tiempo, cuando llegaban a la celebración se encontraban sólo con los restos. Al final de la cena tenía lugar la acción sacramental sobre el pan y el vino. Pablo reaccionó contra esta situación de forma polémica y crítica. Éste era un conflicto social entre ricos y pobres, pero con una dimensión teológica ${ }^{15}$.

En los cap. 8-10 el apóstol trata los problemas sacramentales y de conciencia que originaba en algunos componentes de la comunidad la participación en los banquetes sacrificiales, donde se comía carne inmolada a los ídolos ( $\left.\varepsilon^{\prime} \delta \omega \lambda o ́ \theta v \tau o v\right)$, pues se trataba en la mayoría de la veces de carne de cerdo ${ }^{16}$. Algunos cristianos de Corinto, los "fuertes", comían carne inmolada a los ídolos sin ningún remordimiento de conciencia a causa de su "gnosis" (conocimiento, saber). Para justificar su praxis aducían algunas frases de Pablo, p.e. "Todo está permitido" $(6,12 ; 10,23)$. Los "débiles", escandalizados con la actitud de los "fuertes", no querían participar en tales banquetes a

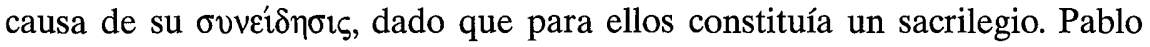
argumentó en esta ocasión contra los "fuertes", pues incluso los mismos derechos legítimos tenían sus límites, cuando el ejercicio de esos derechos pudiera poner en peligro la fe de otros cristianos. Por eso aconseja Pablo a los "fuertes" que renuncien a su libertad por amor al hermano débil. ¿Quiénes eran los

15. Un estudio amplio de este pasaje nos ofrece $A$.C. Thiselton, The First Epistle to the Corinthians. A Commentary on the Greek Text (NIGTC), B. Eerdmans - Paternoster Press, Grand Rapids, Mi. - Carlisles 2000, 848-899.

16. Para ello véase M.M. Mitchell, Paul and the Rhetoric of Reconciliation. An Exegetical Investigation of the Languaje and Composition of 1 Corinthians, Westminster John Knox Press, Louisville 1991,126-130. 
débiles y los fuertes? Los fuertes parece que defendían tendencias gnósticas. G. Theißen (253) los identifica con el grupo de los pocos "sabios, poderosos y de buena familia" $(1,26)$, es decir, la clase alta de la comunidad y los débiles con los cristianos pobres y de clases humildes. Tenemos que afirmar y subrayar por medio del texto 1 Cor de 8,7 ("acostumbrados hasta ahora al ídolo"), que los débiles hay que localizarlos dentro de las filas de los que una vez habían sido gentiles ${ }^{17}$. Hay que insistir en este dato, dado que hay un grupo amplio e influyente de exégetas que quieren identificar a esos débiles con judeocristianos. Éstos habrían apelado probablemente a las clausulas de Santiago (Hech 15), lo cual no es el caso aquí. Además, habrían exigido la circuncisión y la observancia de fiestas judías como había sucedido en Galacia y Filipos.

Entre las diversas situaciones que Pablo 18 tuvo que afrontar en 1 Cor, estaba la problemática de la división de la comunidad en facciones, las cuales se orientaban y se basaban en el culto a la personalidad de algunos de los apóstoles o misioneros. A esta división dedica Pablo el pasaje 1 Cor 1,10-4,21, cuyo texto forma una unidad formal cerrada ${ }^{19}$. La importancia de estos versos para la compresión de 1 Cor la ha puesto de manifiesto M.M. Mitchell mediante las reglas de la retórica. Esta autora considera 1 Cor 1,10 como la $\pi \rho{ }_{0} \theta \varepsilon \sigma 1 \zeta$, la tesis o afirmación central de toda la carta, por lo que la unidad de la comunidad y el cese de las facciones en Corinto sería el objetivo principal de la carta: la epístola sería una respuesta a la división de los Corintios en partidos $^{20}$. La estrategia retórica de Pablo va dirigida contra el fenómeno del faccionalismo mismo y no contra cada una de las facciones. Pablo exige de los Corintios la unidad (

17. G. Sellin, "Hauptprobleme" 3004; H.-J. Klauck, 1. Korintherbrief (NEB.NT 7), 3. Aufl.,Würzburg 1992, 62. F. Watson, Paul, Judaism and the Gentiles. A Sociological Approach (MSSNTS 56), Cambridge 1986, 81, caracteriza el problema de los "débiles" de la siguiente forma: "Habrían experimentado un conflicto de lealtades entre su nueva fe y su vieja fe en los dioses paganos".

18. Se pasa por alto que la información de los seguidores de Cloe referente a los

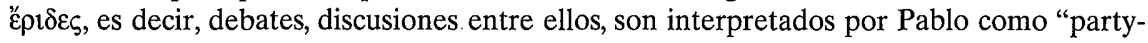
strife". Es el apóstol, no los corintios, quien entendió sus debates como partidos o divisiones de escuela.

19. Cfr. H. Merklein, 1 Kor 113.

20. M.M. Mitchell, Paul 17.66. El objetivo de su estudio es mostrar cómo Pablo, en su argumentación, usa un lenguaje político y diversos topoi para describir la situación en Corinto, la cual califica de faccionalismo, y exigir la reunificación de la iglesia: "Cor is in fact an unified and coherent appeal for unity and cessation of factionalism" (p. 19).

21. Esta expresión se usaba en la literatura griega para describir a personas en un estado de unidad política o social, cfr. M.M. Mitchell, Paul 69s. Para el significado de $\kappa \alpha \tau \alpha \rho-$

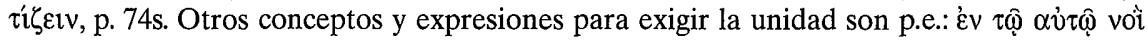
$\kappa \alpha \grave{\varepsilon} \dot{\varepsilon} \vee \tau \hat{n} \gamma \nu \omega ́ \mu \eta$, cfr. p. 76-80. 
La situación era preocupante, pero no se había llegado al extremo de crear verdaderas iglesias separadas, dado que Pablo escribe a "la comunidad" de Corinto $(1,2)$, y el "vosotros"22 de sus interlocutores no es sectorial, sino que se refiere a todos los cristianos de la ciudad. Una distinción explícita aparecerá en 4,18 refiriéndose a algunos que se jactan orgullosos, pensando que Pablo tiene miedo de venir a Corinto para un encuentro personal. La situación no se puede reducir, como posteriormente se verá, a un simple y puro litigio entre creyentes individuales, pues no haría justicia a los slogans de 1,12.

El campo semántico de esos versículos muestra claramente la problemática de la división y de los conflictos en Corinto en el interior de la misma comunidad cristiana. Esta tensa situación viene expresada en la carta median-

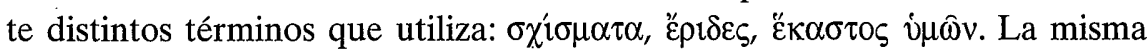
temática se encuentra posteriormente en $3,3 \mathrm{~s}$ y 3,21s. El término $\sigma \chi^{\prime} i \sigma \mu \alpha \tau \alpha^{23}$ tiene un papel importante en la carta $(1,10,11,18 ; 12,25)$. El significado de $\sigma \chi i \sigma \mu \alpha$ (división, disensión) no es lo que se entiende hoy por "cisma" dentro de la iglesia y tampoco hace referencia a la diferencia de diversas opiniones teológicas ${ }^{24}$. Para L.L. Welborn este término no tiene nada que ver con una herejía religiosa ni con una inofensiva pandilla o camarilla, sino con facciones enfrascadas en una lucha por el poder ${ }^{25}$. Con este concepto, Pablo quiso

22. El pronombre personal de $2^{\text {a }}$ persona plural ( $\dot{v} \mu \varepsilon \hat{\iota} \varsigma$ ) se repite en varias ocasiones: 1,$26 ; 1,30 ; 2,1-3 ; 3,21-23 ; 4,14-15 ; 4,16 ; 4,17 ; 4,21$.

23. El singular $\sigma \chi i \sigma \mu \alpha$ en 1 Cor 1,11 se encuentra en algunos manuscritos: $\mathrm{P}^{46} 33.630$ $p c$.

24. Para el significado y empleo del término véase W. Schrage, 1 Kor 138s., n. $246 . \mathrm{El}$ verbo $\sigma \chi i \zeta \omega$ aparece en 9 ocasiones en los evangelios (con el significado de rasgar o partir cosas), y en dos ocasiones en Hech 14,4; 23,7. Lucas lo usa en Hechos para la toma de partido entre Pablo y sus enemigos. El sustantivo $\sigma \chi i \sigma \mu \alpha$ es usado en lo siguientes pasajes: Mc 2,21 par.; Jn 7,43; 9,16; 10,19. C. Maurer, $\sigma \chi i \zeta \omega$, in: ThWNT VII (1964) 964s., entiende el empleo de esta palabra por parte de Pablo como diferencias doctrinales y de programas, cuyas formulaciones no estaban fijadas, y mediante las cuales se diferenciaban las distintas tendencias entre sí. En los escritos de los Padres Apostólicos los $\sigma \chi i \sigma \mu \alpha \tau \alpha$ son vistos como divisiones (escisiones) en relación con conflictos y envidias (1 Clem 2,6;46,5.9; Hermas VIII 9,4). Según M.M. Mitchell, Paul 70, $\sigma \chi i ́ \sigma \mu \alpha$ es uno de entre tantos conceptos políticos que Pablo utiliza para describir la división en Corinto. El término significa: "a division or a rift within the social fabric of the community". Esta autora aporta textos, además de los de $C$. Maurer 960, para justificar el empleo metafórico de $\sigma \chi^{\prime} \zeta \xi \iota \downarrow$ con el sentido de ruptura de

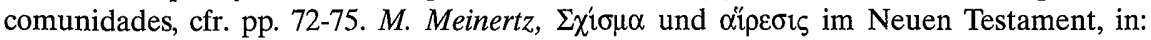
BZ.NF 1 (1957) 115, opina que este concepto se puede traducir en sentido "amplio" (transferido) como conflicto, altercado, desaveniencia de opinión y/o perturbación de la paz. Pero en ningún lugar se encuentra este término usado como alusión o insinuación para indicar la relación del judaísmo y la Iglesia.

25. L.L. Welborn, Politics \& Rhetoric in the Corinthian Epistles, Mercer University Press, Macon 1997, 7. 
expresar que la comunidad estaba dividida claramente de forma peligrosa. Por tanto, serían las desavenencias existentes en el seno de la comunidad producidas por los grupos que pretenden seguir a diversas autoridades. No se deben considerar los acontecimientos en Corinto como meras diferencias teológicas o competencia personal entre distintos misioneros, sino una lucha por el poder.

Otro concepto usado para expresar la disensión en la comunidad es la palabra ěpıৎ (disputa, discordia, reyerta, rivalidad, altercado, pelea...), y que las biblias en español suelen traducir como "contienda" o "discordia". Pablo se entera por los de Cloe que hay discordias en la comunidad (1 Cor 1,11), es decir, que hay facciones ${ }^{26}$. En 1 Cor 3,3, el término va unido a $\zeta \tilde{\eta} \lambda \circ \varsigma$ y describe así la fuente $\mathrm{u}$ origen del comportamiento divisorio de los corintios; significa que hay disensión en la comunidad ${ }^{27}$. Parece ser que este concepto se refería en la literatura griega también a los conflictos o disputas políticas. Se discute entre los estudiosos, si "̌pı $\delta \varepsilon \varsigma^{28}$ es sinónimo de $\sigma \chi i \sigma \mu \alpha \tau \alpha$. Con este término Pablo quería expresar que la comunidad se encontraba claramente dividida de forma peligrosa para su superviviencia. Otros conceptos y términos usados pertenecientes al mismo campo semántico y que indican divisiones,

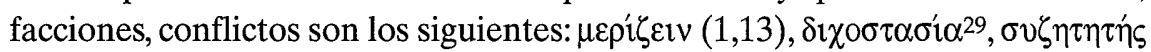

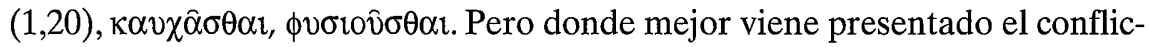

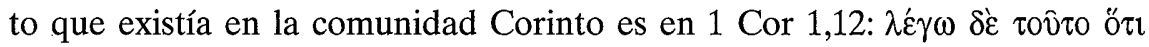

26. Para la discusión sobre si los de Cloe o Estéfanas llevaron al apóstol información oral o escrita véase E.Sch. Fiorenza, "Situation" 395.

27. En Rom 13,13 y 2 Cor 12,20 हैpı $\varsigma$ se haya también unido a $\zeta \tilde{\eta} \lambda \circ$; en ambos casos se trata de rivalidades y celos que ponen en peligro la armonía de la comunidad, cfr. $H$. Giesen, ع̌pıs, en: DENT I (1996) 1581s. En Basilius, Prologus 7 (de juicio Dei) 31,660,11 y

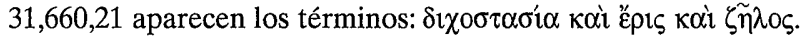

28. Así traducen este concepto: $H$. Conzelmann,1 Kor 44; H. Merklein, 1 Kor 153; W. Schrage, 1 Kor 133. Con "disputas, discusiones, querellas" ("Streitereien") A. Strobel, Der erste Brief an die Korinther (ZBK.NT 6,1), Zürich 1989, 32. Con "Zank [riña, reyerta, camorra] und Streit" H.-J. Klauck, 1 Kor 21. M.M. Mitchell, Paul 81, prefiere la traducción fuerte de"quarrels". L.L. Welborn, On the Discord in Corinth: 1 Corinthian 1-4 and Ancient Politics, in: JBL 106 (1987) 86, entiende la palabra como una"hot dispute, the emotional flame that ignites whenever rivalry becomes intolerable". Este término viene empleado en la literatura griega referido a conflictos políticos: Appianus, BC II 2,6; III 86,375; Josephus, AJ XIV 470; Plutarchus, Caes. 33. Otros pasajes se encuentran en M.M. Mitchell, Paul 81s., n. 93 ss.

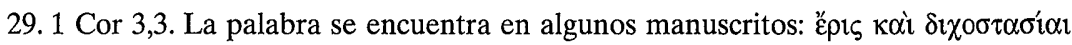
$\mathrm{P}^{46} \mathrm{D} 33$ 88.... Cfr. los argumentos aducidos para la autenticidad de esta variante en $L . L$. Welborn, "Discord" 88, n. 13: un término típico paulino (Gal 5,20; Rom 16,17). Otras citas de la literatura antigua: 1 Mac 3,29; 1 Clem 46,5; Diodorus, XXXV 25,1; Herodotus, 5,75; Plutarchus, Moralia 478e-479a. 


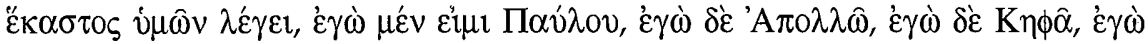
$\delta$ ' $\mathrm{X} p \iota \sigma \tau 0 \hat{v}$. = Me refiero a que cada uno de vosotros dice: 'yo soy de Pablo', 'yo de Apolo', 'yo de Cefas', 'yo de Cristo'”. Estas expresiones han sido denominadas en la investigación exegética como las consignas o "slogans" de los partidos, y serán las que analizaremos posteriormente.

Pablo no nos indica el motivo de esos $\sigma \chi i \sigma \mu \alpha \tau \alpha$, o por qué surgieron dichas discordias. El origen de tal situación habría que buscarlo tal vez no en un sólo motivo, sino más bien en un complejo conjunto de interacciones. Entre las causas que jugaron un papel importante habría que destacar: factores étnicos ${ }^{30}$, económicos, culturales, políticos y sociológicos, así como concepciones o afirmaciones teológicas ${ }^{31}$ (un debate sobre la sabiduría $\sigma 0 \phi i ́ \alpha \lambda o^{-}$ $\gamma \circ v$, $\sigma o \phi i ́ \alpha \tau \hat{\omega} v \sigma o \phi \hat{\omega} v^{32}$ ) y distintas praxis de la misión ${ }^{33}$. Hay que resaltar que una reducción del problema a puros motivos teológicos no aclara la cuestión. Históricamente es incluso hasta cuestionable que la comunidad de Corinto hubiera constituido una unidad desde su fundación ${ }^{34}$.

Ya en los primeros siglos del cristianismo llamó la atención de los Padres de la Iglesia la división de la comunidad de Corinto. Pocos años más tarde de la composición de 1 Cor, el escritor de 1 Clem 47,1-3, menciona la situación conflictiva dentro de la comunidad en tiempos de Pablo. Así mismo, el Canon Muratonianus considera la carta de 1 Cor como una epístola que combate el faccionalismo: "primun omnium corintheis schemae haereses interdicens"35.

30. Conflictos entre griegos y judíos. Es importante la precisión de P.Richardson, On the Absence of 'Anti-Judaism' in 1 Corinthians, in: P. Richardson - D. Granskou (ed.), AntiJudaism in Early Christianity. Bd. 1: Paul and the Gospels, Studies in Christianity and Judaism 2, Waterloo: Wilfred Laurier University Press 1986, 59-74. Este autor afirma que en 1 Cor no hay expresiones antijudaístas porque Pablo estaba preocupado en mediar pacíficamente entre los distintos grupos.

31. La rivalidad expresada en los grupos asociados a este o a aquel "padre espiritual" tenía relación con la búsqueda de la sabiduría (cfr. 3,18$)$, unida al vanto $(3,21)$ y a la orgullosa arrogancia frente al grupo contrario y de su líder $(4,6)$. 1997.

32. Cfr. B.W. Winter, Philo and Paul among the Sophists (MSSNTS 96), Cambridge

33. Para G. Theißen, "Legitimation" 214s., estamos ante un conflicto de concepciones de la misión y del tipo de misionero.

34. Según H.-J. Klauck, Hausgemeinde 39s, Pablo habría intentado crear por medio de la colecta una unidad de distintas comunidades domésticas.

35. T. Zahn, Geschichte des neutestamentlichen Kanons, Erlangen - Leipzig 1890, Bd. 2, pt. 1,6-7. Palabras semejantes se encuentran en Tertullianus, De baptismo 14: "quoniam schismata et dissensiones inter illos movebantur" (PL 1.1324). Baste mencionar que Chrysostomos, Homi I-XLIV in 1 Cor (PG 61.9-382), en su comentario a la 1 carta a los Corintios utiliza el término $\sigma \chi i \sigma \mu \alpha$ en 23 ocasiones. 
Pero no sólo los Padres de la Iglesia, sino también los exégetas modernos se han dedicado a estudiar el tema de la división, escisiones o grupos dentro de la comunidad. Se ha escrito mucho sobre el tema, pero hasta ahora no se ha llegado a una solución satisfactoria para todos. En una cosa están todos de acuerdo: la comunidad tenía problemas internos. Se discute el grado de división de la comunidad. Entre los estudiosos se encuentran dos posturas generales: a) Quienes consideran que la comunidad estaba desunida, dividida en grupos o "partidos" 36 , los cuales apelaban a la autoridad de uno de los misioneros $(1,12)$. b) Otros autores, por el contrario, hablan de división interna seria, pero no se podría uno figurar a esta iglesia dividida en "partidos", pues Pablo se dirige a toda la comunidad, y "ya que no hay nada en la carta misma que dé alguna insinuación de cómo podrían identificarse tales partidos"37. Por consiguiente, postulan la siguiente situación histórica: estamos ante una situación de conflicto entre la iglesia y su fundador, pero en la comunidad de Corinto no existían partidos, sino sólo algunos conflictos por motivos no dogmáticos ${ }^{38}$. "Esto no niega que la iglesia estuviera experimentado contiendas internas, sino que afirma que el principal problema de 'división' se hallaba entre Pablo y algunos miembros de la comunidad que estaban empujando a la iglesia entera hacia una forma antipaulina de ver las cosas"39. Por tanto, la diferencia entre estas dos posturas estriba en el grado de división interna.

Los estudiosos han intentado encontrar un motivo unificante singular subrayando los temas fundamentales de 1 Cor, con el objetivo de identificar a los oponentes. Se han buscado motivos teológicos, filosóficos, sociales...:

36. La expresión "partidos" ha adquirido con el paso del tiempo (desde Chr.F. Baur) una impronta teológica y una connotación política-eclesial. Aunque este concepto es problemático, ha sido aceptado y adoptado por la mayoría de los estudiodsos. Otras expresiones usadas son p.e. facción, grupos, camarilla...

37. G. Fee, Primera Epístola a los Corintios, Nueva Creación, Grand Rapids, Mich. 1994, 8; Ben Witherington, Conflict 84. Una posición ambigua defiende J.K. Chow, Patronage 94.

38. Esta postura la defiende J. Munck, Paulus und die Heilgeschichte (Ajut.T 6), København 1954,127-161, o en su artículo "Die Gemeinde ohne Parteien". Él habla de una comunidad sin partidos: es por tanto una cuestión, no de facciones, sino simplemente de división entre los miembros de la iglesia por razones no teológicas. N.A. Dahl, Paul and the Church at Corinth according to 1 Corinthians 1:10-4,21, in: W.R. Farmer (ed.), Christian History and Interpretation, FS J. Knox, Cambridge 1967, 315: "It is fairly generally agreed that in 1 Corinthians 1-4 Paul is addresing the church at Corinth as a whole, and that it is not possible to take any one section to refer to any one of the 'parties', if there were any parties at all".

39. G. Fee, 1 Cor 9. 
puede que el gnosticismo, quizás fervientes carismáticos, tal vez disensiones argumentativas como tal (M.M. Mittchel), tal vez la riqueza y las distinciones sociales (G. Theißen) o el honor y el prestigio (S.M. Pogoloff, A.D. Clarke). En los últimos años se han llevado acabo distintas investigaciones a nivel sociológico sobre los adversarios paulinos, las cuales intentan explicar la actitud beligerante de los enemigos basándose en las reglas de la "clientela" vigentes en aquella época ${ }^{40}$.

La mayoría de los estudiosos consideran las categorías de sophia (sabiduría) y logos (palabra), a menudo estrechamente vinculadas, como el centro del contencioso entre Pablo y sus interlocutores. El consenso acaba si se quiere precisar más el mensaje fundamental de los corintios y se quiere precisar el contenido de dichas categorías, acentuando más unos aspectos u otros. Así se pueden indicar cinco tendencias, según se les otorgue a los términos sophia y logos una orientación filosófico-especulativa, una doctrina gnóstica, un entusiasmo con tintes carismáticos, una especulación cristológica-sapiencial de matriz judaico-alejandrina o judaico-palestinense, y finalmente el arte de decir o la elocuencia.

a) Según la hipótesis de orientación filosófico-especulativa, los corintios entendieron el mensaje cristiano como un sistema filosófico racional por lo

40. Hay que mencionar a $P$. Marshall, Enmity 182-218. Este autor denomina a los enemigos "hybrists". Este término era una compleja noción que incluía el 'orgullo' o 'arrogancia' asociado con el rico y poderoso, y conllevaba la noción de superioridad y presunción. $\mathrm{Su}$ análisis del conflicto entre Pablo y los corintios se basa en las convenciones antiguas de amistad y enemistad. Él explica su tesis de enemistad en los siguientes términos: "The Corinthian offer of aid consisted an offer of friendship, in the form of a gift made to Paul by certain wealthy Corinthians [hybrists]... His refusal of their gifts was construed by them as a hostile act and a refusal of friendship and his acceptance of gifts from his Philippian friends led to the charge that he viewed the Corinthians unfavourably. This gave rise to suspicion and invective and an attempt to displace him as the apostle in Corinth with invitations being sent to other apostles. His enemies commenced to ridicule him as an inconstant person, or false friend and flatterer who accommodated to others and different circumstances to please himself and disregarded his social and moral obligation" (p. 257). Su tesis puede explicar las dinámicas conflictivas socio-culturales entre los Corintios y Pablo, pero no explica por qué cuestionaron su liderazgo y el rechazo a su regreso. A.D. Clarke, Leadership 112s.: "Paul's first point of criticism of secular leadership is the exclusive loyalty which each of the Corinthians were showing to particular leading 'patron' figures of the church... In the Corinthian congregation a similar loyalty of dependence [patron-client] was exercised by some towards the significant, leading figures of Paul, Apollos and Cephas". T.L. Carter, 'Big Men' in Corinth, in: JSNT 66 (1997) 45-71: “The conflict arises as a result of the 'low-group / high-grid' competitive individualism of the local patrons, wo disregard group boundaries, and who are seeking to increase their own following at Paul's expense in a way that reflects the surrounding urban culture" (p. 69). J.K. Chow, Patronage and Power: A Study Social Networks in Corinth, Sheffield 1992. 
que intentaban formular una doctrina intelectualmente elaborada y especulativa. Sería una variante de la sophia o filosofía griega con tintes cristianos. En contra de tal tesis hay que subrayar que no encontramos ningún tipo de intelectualismo. Algunos han visto que los oponentes estaban imbuidos más bien de un espíritu entusiástico: el creyente está lleno del espíritu y se convierte en un ser libre de las ataduras del mundo, un yo pneumático superior al común de los mortales, y por tanto gozaban ya de la salvación.

b) No muy lejano de esta interpretación espiritual entusiástica está la hipótesis que considera a los corintios como gnósticos. Ha sido bastante común designar a los oponentes de Pablo, incluso a esos de 1 Cor, como gnósticos. El mayor defensor de esta teoría en las últimas década ha sido $W$. Schmithals ${ }^{41}$, quien considera los oponentes en Corinto como gnósticos judíos. El problema del origen, naturaleza e historia del gnosticismo es complejo. Se puede decir ordinariamente que mientras ideas gnósticas, las cuales posteriormente constituyeron el sistema gnóstico, se pueden encontrar en 1 Cor, no se puede concluir que 1 Cor pueda ser interpretada a la luz del "gnosticismo" sin distorsionar la realidad. La tesis de Schmithals de identificar a los oponentes con los gnósticos tiene algunos puntos débiles y criticables. Algunas de las ideas principales de 1 Cor, tales como el lenguaje pneumatikos-psychikos, no han sido discutidas adecuadamente por Schmithals. Aunque si los oponentes pudieran ser calificados como "gnósticos o proto-gnósticos, una especie de gnosis, gnosis in statu nascendi", tal identificación no ofrece una explicación para los problemas que Pablo trata en 1 Cor 5,1-6,11. Muchos estudiosos concluyen que si bien es verdad que se pueden encontrar paralelismo en la terminología, no es necesario recurrir al gnosticismo para explicarlos, sino más bien a la cultura, pero no se encuentran trazas de un gnosticismo ni referencias a alguna gnosis exotérica.

c) Helenistas-entusiastas ${ }^{42}$ : Teniendo en cuenta el trasfondo cultural helenista religioso- filosófico de la ciudad de Corinto, algunos estudiosos han visto los problemas en la iglesia de Corinto como originados de la interacción con el pasado pagano y su ambiente. Así, E. Käsemann ${ }^{43}$ opina que los Corintios eran helenistas, y los problemas en Corinto eran manifestaciones de

41.W. Schmithals, Die Gnosis in Korinth. Eine Untersuchung zu den Korintherbriefen (FRLANT 48), Göttingen 1956.

42. Con el término "entusiasmo" designa G. Sellin, "Hauptprobleme" 3017: "Es handelt sich um ein hellenistisches bzw. helenistisch-jüdisches Konzept, wonach das Göttliche jederzeit die Seele eines Menschen erfüllen kann bzw. die Seele des Menschen in Ekstase das Göttliche schaut. Entscheidend ist dabei die Ausschaltung der zeitlichen Dimension zugunsten des Gedankens einer ewigen Transzendenz".

43. E. Käsemann, Ensayos Exegéticos (BEB 20), Ed. Sígueme, Salamanca 1978, 234. 
una forma helenizada de cristianismo. Así algunos creyentes creían haber alcanzado ya el objetivo de la salvación en el bautismo, y la experiencia cristiana en la tierra significaba para ellos simplemente la representación temporal del ser celeste. La resurrección ya habría tenido lugar y por tanto entendían la religión cristiana como una religión mistérica. A.C. Thiselton describe la posición corintia como una "over-realized" escatología que conduce a una visión entusiástica del espíritu. Los corintios creerían que eran libres y por encima de las obligaciones morales. La cohabitación de un hombre con la esposa de su padre, y el comer la carne de los idolitos son vistos como manifestaciones de una nueva libertad. Esta caracterización de los corintios defendiendo una escatología realizada ha sido criticada en algunos puntos, pero puede explicar la visión teológica de los oponentes en Corinto. G. Fee afirma que todo se puede explicar en la carta teniendo presente sus orígenes grecorromanos. Los corintios pensaron en sus maestros (Pablo y Apolo) en términos semejantes a los filósofos itinerantes. Consideraron su fe como la sofía divina, y que habían alcanzado ya la misma sofía. De ahí el rechazo del evangelio de Pablo y de su persona. Por contra, Pablo intenta reafirmar su evangelio como el mensaje del Mesías crucificado y de reafirmarse a sí mismo como verdadero apóstol ${ }^{44}$.

d) Filosofía helenista-judía: Teniendo en cuenta la situación en Corinto, no tenemos que olvidar el hecho de que algunos miembros cristianos procedían de comunidades judías. Apolo ${ }^{45}$ reunió un grupo entorno a sí. Por lo que algunos estudiosos piensan que tradiciones judeo-helenistas pueden proporcionar el contexto para explicar la religiosidad de los corintios. Así se ha propuesto la teoría de una teología sapiencial inspirada en la especulación judaico-helenística alejandrina presente en el libro de la Sabiduría y en Filón de Alejandría. Según Filón el hombre natural es caduco no sólo en su cuerpo sino también en su alma. Únicamente la inspiración de la sabiduría transcendente lo puede hacer un ser inmortal y le comunica un conocimiento sobrenatural. A esto habría que añadir la especulación sobre el Logos eterno y divino. Todo este sistema de pensamiento se cristianizó. Cristo es entonces la sabiduría eterna, que nos otorga su espíritu capaz de transformarnos en seres pneumáticos y sabios para conocer el misterio de Dios.

44. G. Fee, 1 Cor 18.

45. Ch. Wolff, Der erste Brief des Paulus an die Korinther (THKNT 7), Evangelische Verlagsanstalt, Leipzig 1996, 9s., presupone en Corinto un influjo de la doctrina sapiencial helenista-judaísta, y esta no sería por influjo de Apolo, sino más bien de la sinagoga helenista existente en esa ciudad y a la cual habían pertenecido algunos cristianos. 
R.A. Horsley ${ }^{46}$ ha estudiado los paralelismos entre las tradiciones judeohelenistas y la religiosidad de los oponentes de 1 Cor, y merece la pena destacar sus conclusiones. Según su teoría los corintios estaban imbuidos de una devoción entusiástica a la sabiduría divina, la cual no se identificaba necesariamente con Cristo, a quien consideraban un maestro de la sabiduría divina, un gran mistagogo, tal vez semejante a Moisés en los escritos de Filón. Dado que poseían esta divina sabiduría, los corintios creyeron que habían alcanzado el mayor status espiritual y era gente espiritual. La manifestación empírica de su estatus espiritual transcendental eran su expresión elocuente y su experiencia individual de profecía extática, incluyendo la glosolalia. Al haber alcanzado dicha posición, pensaron que ya no estaban sujetos a las cuestiones corporales y materiales. Por eso negaban la resurrección del cuerpo y no estaban interesados en la cruz de Cristo. Y se atribuían un status superior al de la gente no espiritual.

Esta explicación de Horsley permite explicar la actitud elitista de los corintios. Y dado que 1 Cor 8,4 parece indicar que los corintios aceptaban la idea judía del monoteísmo, esto hace más atractiva dicha tesis. Sin embargo hay que señalar que este autor no soluciona algunos de los problemas que plantea el atender las disputas en los tribunales (1 Cor 6,1-11) ni el rito del bautismo para la muerte (1 Cor 15,29), y los rasgos explícitamente gentiles de la carta, como es la asistencia a las fiestas paganas en los templos de los ídolos. Sería muy difícil imaginarse a un judío de la diáspora participando de tales banquetes, y menos si consideramos la frase paulina: "Sabéis que cuando erais gentiles, os dejabais arrastrar ciegamente hacia los ídolos mudos" $(12,2)$.

Es muy discutido que existiera en Corinto una teología especulativa sobre la sabiduría de origen alejandrino y que se aplicara a Cristo (personificación de la sabiduría divina, preexistente y mediador de la creación y salvación), a la cual el apóstol habría opuesto una teología de la cruz. Es cuestionable que una mayoría de los cristianos de Corinto fueran capaces de tales especulaciones refinadas.

Para apoyar la tesis de que los corintios estaban fascinados con la elocuencia retórica se basan los autores en textos como: $1,17 \mathrm{~b} ; 2,1 ; 2,4 ; 2,13 ; 4,20$. La sophia que Pablo teme que contamine a los corintios sería la retórica. Los interlocutores de Pablo no estaban preocupados por construcciones doctrinales. Los términos logos y sophia no indicarían sistemas de pensamiento filo-

46. R.A. Horsley, Wisdom of Word and Words of Wisdom in Corinth, in: CBQ 39 (1977) 224-239; Idem, Consciousness and Freedom among the Corinthians: 1 Cor 8-10, in: CBQ 40 (1978) 574-589; Idem, 1 Corinthians, Nashville, Abingdon Press 1998. 
sófico o especulativo religioso. Logos significa discurso y sophos elocuente, por tanto se trata de la retórica. S.M.Pogoloff ${ }^{47}$ postula que la retórica estaba íntimamente conexa con el status social; y entre retórica y divisiones había una relación de causa-efecto, en el sentido que la competición, la disputa formaba parte de la retórica clásica, y la disputa crea divisiones. Los corintios se comportaban como la mayoría de los discípulos de los antiguos sofistas y otros maestros, pavoneándose de quién tenía el maestro más convincente. Algunos consideraban a Apolo como el sophos del grupo, como sabio orador. Pablo rechaza tales actitudes ofreciendo modelos de concordia y autosacrificio. A.D. Litfin $^{48}$ ha mostrado en su estudio la importancia que tenía la retórica en la sociedad de Corinto en el siglo I. La elocuencia estaba relacionada con la sabiduría, pues no se trataba simplemente de palabras bonitas sino de pensamientos bien expresados. El término sophos no se aplicaría a los filósofos; se usaba más bien para los sofistas. La situación de Corinto la describe así: La venida de Apolo ha creado una fractura en la comunidad entre quien defiende a Pablo y su evangelio y quien, fascinado por la retórica de Apolo, criticaba al apóstol. Entiende 1 Cor 1,17-25 como la apología paulina contra el criticismo corintio, que su predicación no se podía mesurar con la elocuencia greco-romana.

En esta línea interpretativa también se expresa G. Barbaglio. El conflicto giraba sobre la predicación evangélica de Pablo y no directamente sobre cuestiones cristológicas. Los interlocutores paulinos conservan la adhesión al kerigma de Cristo muerto y resucitado, pero se exaltaban por la habilidad humana del predicador, idolatrado como maestro elocuente en el decir y profundo en el pensar, y criticaban a Pablo por su deficiencia ${ }^{49}$ en el predicar.

B.W. Winter ${ }^{50}$ analiza los problemas en las dos cartas a Corinto desde el trasfondo de los movimientos sofistas. Las disputas (eris) y los celos que criti-

47. S.M. Pogoloff, Logos and Sophia:The Rhetorical Situation of 1 Corinthians (SBL Dissertation Series 134), Atlanta 1992. Para una crítica de esta obra, cfr. M.Mitchell, Paul $89 \mathrm{~s}$.

48. A.D. Litfin, St. Paul's Theology of Proclamation: an investigation of 1 Corinthians 1-4 and Greco- Roman Rhetoric (SNTS Monograph S. 79), Cambridge 1994.

49. G. Barbaglio, La prima Lettera ai Corinzi (Studi delle origini cristiane 16), Ed. Dehoniane, Bologna 1995, 118.

50. B.W. Winter, Philo and Paul among the Sophists (MSSNTS 96), Cambridge 1997. Idem, After Paul left Corinth. The Influence of Secular Ethics and Social Change, B. Eerdmans, Grand Rapids, Mi. 2001, 43: "The Christian community was influenced by the secular educational mores of Corinth. It has also traced the effects of Christians embracing them, with their emphasis on the exclusive relationship of a student to his teacher, and the effect of zealousness in promoting loyalty to one and criticism of others". 
ca Pablo en 1,11 y 3,3 se refieren claramente al movimiento sofista. Pablo se opone radicalmente a un modelo sofista de dirección eclesial (liderazgo ${ }^{51}$ ). El modus operandi de Pablo en Corinto descrito en 1 Cor 2,1-5, ha sido formulado a la luz de las convenciones sofistas de venir a una ciudad y de operar en ella. En 1 Cor 1-4 Pablo ofrece una crítica de la tradición sofista corintia, la cual había criticado su actuación desde los cánones sofistas (2 Cor 10-13). Este autor identifica los oponentes de 1 y 2 Cor, los cuales debían ser de origen judío, pero bien instruidos en la retórica griega. Ellos habrían propuesto la idea que tal preparación elitista era el ideal e incluso un prerrequisito esencial para la enseñanza elevada o para el ministerio eclesial de predicar, especialmente en áreas gentiles. Pablo critica una concepción sofista básica declarando que en la iglesia el maestro pertenece a los discípulos y no viceversa, como era el caso en el mundo secular corintio. La censura de la admiración cristiana por la habilidad retórica ${ }^{52}$ impregna la apología paulina, tanto cuando defiende su modus operandi como cuando formula las definiciones del liderazgo y discipulado cristiano.

Estos intentos explicativos han arrojado luz para entender mejor la situación teológica. Pero parece que ninguna de las explicaciones propuestas sea capaz de explicar todos los detalles de las posiciones teológicas de los corintios. Éstas pueden ser explicadas sin recurrir al gnosticismo, a la luz del medio ambiente sincretista del helenismo con referencia especial a tradiciones judeo-helenista. Estos estudios de la religiosidad de los corintios se centran principalmente en el autocomprensión de los corintios. Pueden aclarar cómo los corintios habrían podido justificar sus acciones en nombre de la libertad de acuerdo con su teología. Pero no explican adecuadamente la realidad social detrás de esas acciones, especialmente esas suscitadas con el contacto con el mundo pagano, ni las implicaciones de tales acciones para las relaciones de poder en la iglesia.

51. Cfr. A.D. Clarke, Leadership.

52. La comunidad, en lugar de su lealtad hacia sus antiguos formadores (maestros), se había convencido de buscar el regreso del experto retórico Apolo. Pero Apolo rechazó su propuesta (1 Cor 16,12). 2 Cor 10-13 sugiere que ante dicha negativa, se reclutaron maestros itinerantes con semejante formación en retórica para instruir a la comunidad. Estos maestros, que tuvieron acceso a las afirmaciones paulinas sobre la tradición sofistas en 1 Cor 1-4, buscaron desacreditar su crítica. Tomando claves de categorías retóricas de esa crítica, ellos montaron un gran ataque contra Pablo subrayando sus deficiencias inherentes como un orador público para justificar el ministerio de estos maestros dentro de la iglesia, y para rechazar cualquier intento de Pablo de restablecer su autoridad perdida durante la visita humillante a Corinto que siguió a la composición de 1 Cor. 
Una vez visto el trasfondo y causas que provocarían los conflictos en la comunidad, vamos a centrarnos ahora en el hecho mismo de las divisiones. Los estudios que presuponen la existencia de grupos o partidos definidos se han centrado fundamentalmente en dos aspectos del problema: el número y la identidad de los grupos contrapuestos.

\section{Los "Partidos" en Corinto}

Los investigadores se enfrentan en primer lugar con el problema de determinar el número de partidos existentes en Corinto. El tema de las disensiones o conflictos internos, que gira en torno a saber a qué autoridad apela cada grupo, se encuentra fundamentalmente en dos pasajes: 1 Cor 1,12 y 3,4.

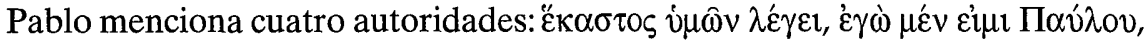

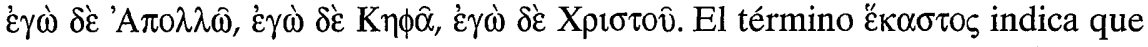
el hecho de invocar o apoyarse en una autoridad concreta era una praxis extendida y común entre la mayoría de las miembros de la comunidad 53 . Pablo quiere decir con ello que prácticamente toda la comunidad estaba "tocada" por los slogans. Esta división en partidos viene también mencionada en 1 Cor 3,4, con la particularidad que vienen nombrados solamente dos

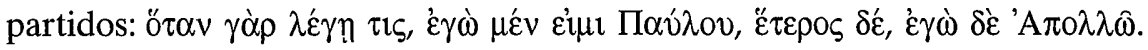
Dado que el apóstol repite sólo el grupo de Pablo y de Apolo, algunos exégetas han llegado a la conclusión de que las disputas en Corinto tenían como constelación fundamental la discrepancia entre los partidarios de Apolo y los de Pablo. Estos dos nombres, junto con el Cefas, aparecen también en 1 Cor

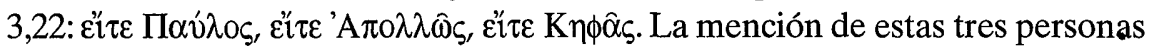
ha llevado a otros estudiosos a suponer que había tres partidos en Corinto.

La expresión usada por Pablo en primera persona (pronombre personal + Eijú + genitivo de un nombre propio ${ }^{54}$ ) no se encuentra en la antigüedad

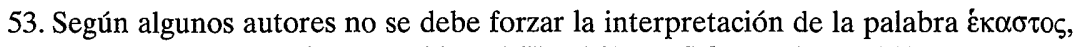
p.e. H. Conzelmann, 1 Kor 46; H. Merklein, 1 Kor 161; W. Schrage, 1 Kor 142. Por contra, otros estudiosos opinan que toda la comunidad estaba implicada en el problema de las divisiones, p.e. A.D.Clarke, Leadership 90, n. 4: "El impacto y dimensión del pronombre

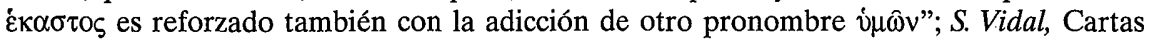
$159, \mathrm{n} .10$.

54. M.M. Mitchell, Paul 85, define el genitivo como genitivo de posesión o de pertenencia. Fr. Blass - A. Debrunner - Fr. Rehkop, Grammatik des neutestamentlichen Griechisch, 17. Aufl., Göttingen, Vandenhoeck - Ruprecht 1990, $\$ 162.7$ cataloga los genitivos de 1 Cor $1,12(3,4.21 ; 6,19 ;$ Hech 27,23$)$ como genitivos de pertenencia, predicativos con el significado de "yo pertenezco a X". 
como una consigna o un slogan político ${ }^{55}$, ni en la filosofía para expresar la pertenencia a una escuela ${ }^{56}$. M.M. Mitchell considera 1 Cor 1,12 semejante a Is 44,5 LXX ( refiere a la pertenencia y a la propiedad. Pablo parece considerar en ella al propietario del culto, la divinidad o Cristo, y no citaría slogans corintios. Esta autora entiende 1 Cor 1,12 como una pregunta retórica, la prosopopeya ( $\pi \rho \circ \sigma \omega \pi 0 \pi \circ i \dot{i} \alpha)$, imitación "con las que sacamos a plazo los pensamientos ocultos aún de nuestros contrarios como si ellos estuvieran hablando consigo mismos" (Quintilianus, Inst 9,2,30). Pablo interpreta estas facciones como un signo infantil y no como una sofisticación o refinamiento político.

¿Cuántos partidos o grupos cristianos tenemos en Corinto? Pablo enumera cuatro autoridades en Corinto $(1,12)$. Tres de los cuatro mencionados son misioneros. Pablo y Apolo vienen nombrados según la sucesión cronológica de su actividad en Corinto. ¿Se pueden identificar dichos partidos? No existe unanimidad entre los exégetas. Un resumen de la historia de la investigación sobre el tema nos mostrará la dificultad que plantea identificar los partidos y su interpretación.

\subsection{El problema del partido de Cristo}

La expresión ' constituye un rompecabezas para los estudiosos, porque es el único grupo que apela a una autoridad que no es humana. Ya J. Chrysostomus (PG 61,24) vio la dificultad de estas palabras y las interpretó como una confesión de Pablo, mientras que las otras tres consignas serían solo seudónimos que debían enmascarar u ocultar a los verdaderos cabecillas. En la exégesis moderna se han propuesto varias posibles explicaciones de esta frase ${ }^{57}:$ a) un grupo judaizante, b) pneumáticos ultraespirituales, c) una interjección y glosa de un copista $^{58}$, d) una lectura errónea del nombre Crispo ${ }^{59}$, o e) como una exageración irónica ${ }^{60}$ de las otras consignas por parte de Pablo.

55. Según G. Sellin, "Hauptprobleme” 3015, estos genitivos no designan simples programas teológicos o de política eclesial, sino dependencias soteriológicas y jerarquías.

56. L.L. Welborn, "Discord" 90s. cita distintas fórmulas griegas de pertenencia. No tienen sin embargo la misma construcción. A. D. Clarke, Leadership 92-95, observa un estrecho paralelismo entre las convenciones del patronato, la lealtad política y sofista con la situación en Corinto. M.M. Mitchell, Paul 84s., se expresa claramente: "Una réplica exacta de la fórmula de 1 Cor 1,12 en la literatura política antigua no ha sido encontrada en la historia de la exégesis de 1 Cor" (p. 85).

57. Cfr. A.C. Thiselton, 1 Cor 129-133. 
Para apoyar la suposición de que aquí tenemos una glosa marginal que un lector antiguo introdujo en el texto, se aducen algunas suposiciones, como que un copista indignado por las divisiones introdujo en el margen "yo soy de Cristo". Un copista posterior interpretaría esta glosa marginal como una omisión no intencionada y por tanto la incorporó en el texto normal. Pero esta explicación es mera conjetura. Otros autores consideran la frase como una glosa por el hecho de que 1 Cor 3,22 solo menciona a Pablo, Apolo y Cefas, y también que el autor de 1 Clem 47,3 tratando el tema de las divisiones unos años más tarde sólo menciona los tres nombres ${ }^{61}$. Sin embargo, el texto aparece en los mejores manuscritos, por eso se descarta la suposición de una glosa. Además, según las reglas de la crítica textual no se comprende por qué un lector iba a introducir en el texto una glosa que le creaba problemas. También se ha intentado entender la expresión "yo soy de Cristo" como palabras de los que no pertenecían a ningún partido, como antítesis de Pablo o como complemento de las respectivas palabras especiales.

Entre las interpretaciones propuestas para caracterizar e identificar el partido de Cristo, mención especial merece, por su influencia en la historia de la investigación, la hipótesis de F.Ch. Baur62, quien considera al partido de Cristo como un grupo judaizante. Este autor presuponía en Corinto dos grupos opuestos, los pagano-cristianos y los judeocristianos. Los partidarios de

58. J. Weiss, 1 Kor xxxviii. 15ss.; U. Wilckens, Weisheit und Torheit. Eine exegetischreligionsgeschichtliche Untersuchung zu 1 Kor 1 und 2 (BHTh 26), Tübingen 1959, 17, n. 2; H.-M. Schenke - K.M. Fischer, Einleitung in die Schriften des Neuen Testaments, Bd. 1, Gütersloh 1978, 93.

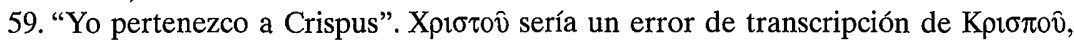
cuyo nombre aparece en el v. 14. Esta teoría fue defendida por $R$. Perdelwitz, Die sogenannte Christus-Partei, in: ThStKr 84 (1911) 180-204. W. Schrage, 1 Kor 147, critica dicha suposición, pues es difícil explicar y suponer que un lector hubiera añadido una glosa, la cual causaba más dificultades. Tampoco se explica que $1 \mathrm{Clem}$ 47,3, quien menciona tres grupos, no mencione el grupo de Crispus, si éste hubiera existido en Corinto.

60. Ph. Vielhauer, Geschichte der urchristlichen Literatur. Einleitung in das Neue Testament, die Apokryphen und die Apostolischen Väter, Berlin - New York 1975, 136s.; J. Munck, Paulus 127ss; N.A. Dahl, "Paul" 329; G. Lüdemann, Paulus II 118, n. 48.

61. Cabe destacar el cambio de orden de los personajes: Pablo, Cefas y Apolo, y la sus-

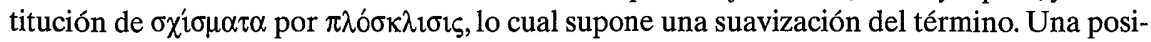

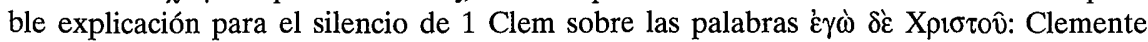
habría entendido esta locución como un comentario de Pablo, y por eso lo habría suprimido, cfr. C.K. Barrett, Christianity in Corinth, in: Idem, Essays on Paul, London 1982, 5. Según A. Lindemann, Die Clemensbriefe. Die Apostolischen Väter I (HNT 17), Tübingen 1992, 139, el autor de 1 Clem no puedo integrar esta locución. 
Pablo y Apolo constituían el grupo de los pagano-cristianos, mientras que en el grupo de los judeocristianos estaban integrados los partidarios petrinos y el partido de Cristo, quienes eran más radicales y decían tener una relación más directa con Cristo. Esta tesis, tal y como ese autor la formuló, no viene defendida hoy por nadie, sino que ha sido modificada ligeramente. Se ha criticado esta propuesta por presuponer distintos grupos o partidos en base a concepciones teológicas. Sin embargo, aquí no se discuten aspectos doctrinales.

La obra de W. Lütger 63 dio otro impulso a la investigación. Este estudioso opinó que los enemigos de Pablo en el partido de Cristo no eran judaístas, sino pneumáticos libertinistas y extáticos, quienes defendían una ideología gnóstica e ideas entusiastas. Este grupo no reconocería a ninguna otra autoridad o fuente de revelación que no fuera la del Cristo espiritual glorificado. Esta hipótesis abrió un nuevo camino en la investigación, que han seguido muchos investigadores en campo alemán hasta hace unas décadas. Hay que mencionar sobre todo W. Schmithals ${ }^{64}$. Según este exégeta, en Corinto se trataba de disputas entre gnósticos entusiastas (partido de Cristo) y los partidarios comprometidos con la tradición apostólica de Pedro, Apolo y Pablo. Los pneumáticos apelaban a una revelación directa, la cual creyeron recibir en éxtasis. Pero no existe ninguna indicación dentro del corpus paulino para una posible identificación del partido de Cristo con una tendencia teológica o sociológica concreta dentro del cristianismo 65 .

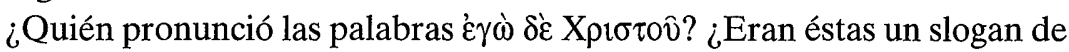
un partido paralelo y análogo a los otros tres? ¿O más bien es un comentario de Pablo66? Otros, por el contrario, afirman que la expresión "yo pertenezco a Cristo" pertenece al inventario de legitimación de los glosolalos que apelaban a Pablo ${ }^{67}$, por tanto servía para legitimar su propias aspiraciones.

62. F.Chr. Baur, Die Christuspartei in der korinthischen Gemeinde, der Gegensatz des petrinischen und paulinischen Christenthums in der ältesten Kirche, der Apostel Petrus in Rom, in: ders., Ausgewählte Werke in Einzelausgaben, hrsg. v. K. Scholder, Bd. I: Historischkritische Untersuchungen zum Neuen Testament, Stuttgart - Bad Cannstatt 1963, 1-146. Véase M.D. Goulder, ¿ОФIA in I Corinthians, in: NTS 37 (1991) 516- 534, para quien las palabras de sabiduría serían en estas comunidades judeocristianas "the halakhic rulings of Jewish Christians" (p. 526). Una crítica a éste autor la encontramos en D.P. Ker, Paul and Apollos - Colleagues or Rivals?, in: JSNT 77 (2000) 80s.

63. W. Lütgert, Freiheitspredigt und Schwarmgeister in Korinth. Ein Beitrag zur Charakteristik der Christuspartei (BFChTh 12,3), Gütersloh 1908.

64. W. Schmithals, Gnosis 188.

65. No se pueden relacionar los pasajes de 2 Cor 10,7 y Mc 9,41 con 1 Cor 1,12, porque reflejan diferentes situaciones. 
Es difícil determinar si existía o no el partido de Cristo. Son muy pocos los exégetas que aceptan la existencia de cuatro partidos en Corinto68. Para ello se apoyan en la tradición textual, tal como se encuentra en los manuscritos. Filológicamente es problemático tomar una decisión. A pesar de la falta de una cesura sintáctica ${ }^{69}$, parece más aconsejable inclinarse por considerar las palabras como una exageración retórica de Pablo con la que pretendía mostrar lo absurdo ${ }^{70}$ de la formación de grupos. Pablo quiere decir: Se ha llegado tan lejos que se reclama a Cristo para sí mismo y para su grupo ${ }^{71}$. Esta exageración retórica es más clara en el v. 3,22s: en primer lugar vienen mencionados los tres posibles partidos, después continúa con otros elementos que pertenecen a la comunidad. La comunidad pertenece a Jesús y éste pertenece a Dios. Si la expresión "vosotros sois de Cristo" indicara un partido, entonces tendríamos que contar con la existencia de un quinto partido, es decir, con el partido de Dios, lo cual no creo que intentara decir Pablo. Otro argumento

66. No creo que sea defendible la postura de $S$. Pétrement, A Separate God. The Christian Origins of Gnosticism, London 1991, 248. Ella considera las consignas no como los slogans de un partido, sino como especificación o étiqueta de un bloque de cristianos libres: "La afirmación 'yo pertenezco a Cristo' puede significar que uno no quiere tomar partido, que uno se contenta con la fe en Cristo, la fe común de todas las tendencias".

67. Así opina H. Merklein, 1 Kor 146, pero no excluye que otros grupos cristianos pudieran haber empleado el slogan de Cristo para sí. G. Sellin,"Hauptprobleme" 3016, quiere reconocer en la consigna de Cristo una expresión de autoconciencia apostólica del mismo Apolo: La consigna de Cristo es la consigna de un apóstol que se entiende a sí mismo como intermediario entre los suyos y Cristo. Expresa la autocomprensión de Apolo. "Paulus dreht die Hierarchie funktional um: die Gemeinde selber ist Christus-unmittelbar, und die Apostel sind funktional der Gemeinde untergeordnet", en G. Sellin, Das "Geheimnis" der Weisheit und das Rätsel der "Christuspartei" (zu 1 Kor 1-4), in: ZNW 73 (1982) 95. S. Vidal, Cartas 159, n. 10, interpreta la expresión como "una afirmación de los grupos de Pablo y de Apolo en sentido exclusivista".

68. G. Barbaglio, 1 Cor 110.125; Ch. Wolff, 1 Kor 28; C.K. Barrett, Commentary on the First Epistle to the Corinthians, Black, London $1972^{2}$, 45. Este investigador atribuye al partido de Cristo el material "controvertido" y ofrece una posible caracterización del partido: "Ellos eran un grupo para quien Cristo significaba algo como 'Dios, libertad e inmortalidad', donde Dios significa un monoteísmo filosófico refinado; libertad significa emancipación de los rigores puritanos de las autoridades bárbaras de Palestina en un ambiente de autorealización". G. Fee, 1 Cor 67s., define a estos hombres como individuos, los cuales se consideraban parte de una élite espiritual.

69. H. Conzelmann, 1 Kor 47, afirma la existencia del grupo de Cristo debido al paralelismo en la formulación con los otros grupos. H. Merklein, 1 Kor 116, considera la posibilidad de poder diferenciar a nivel semántico los tres primeros slogans (¡hombres!) del cuarto.

70. Contra esta tesis cfr. G. Sellin, "Hauptprobleme" 3011. Este autor no ve una antítesis en el cuarto slogan, sino que simplemente continúa la enumeración.

71. W. Schrage, 1 Kor 148. 
para la mención del partido de Cristo sería la pregunta retórica en el v. 13a (¿está Cristo dividido?). Creo que estas palabras son un comentario irónico fruto de la retórica paulina, pues plantearía más problemas suponer que el nombre de Cristo se pudiera colocar al mismo nivel que los nombres de Pablo, Cefas o Apolo. Si hubiera existido un partido de Cristo en Corinto, no cabe la menor duda que Pablo hubiera reconocido su pertenencia a él, o hubiera corregido la confesión exclusivista en Cristo ${ }^{72}$. Pablo quiso subrayar con esta expresión que en Corinto mediante la pertenencia a alguno de los grupos existentes estaba en peligro de hecho la pertenencia fundamental y exclusiva a Cristo. Pablo pretendía indicar con la expresión "yo soy de Cristo" que era absurdo que los diversos grupos de Corinto apelaran a autoridades humanas en vez de reconocerse cristianos.

\subsection{El partido de Pedro}

De los textos 1 Cor 1,12 y 3,21s. se pudiera concluir la existencia de un grupo en Corintio que considera a Pedro como jefe o dirigente propio o escoge su nombre como slogan de su grupo ${ }^{73}$. ¿Qué papel jugaba Pedro en los conflictos en Corinto? Una visita y la actividad misional de Pedro en esta ciudad es discutida. Es difícil decidir si estuvo realmente en Corinto ${ }^{74}$. Ni el NT ni la literatura cristiana antigua nos proporcionan alguna indicación al respecto $^{75}$. Lo que sí se puede afirmar es que los cristianos de Corinto conocían la importancia de este personaje dentro de la Iglesia, pues de otro modo no se entendería su mención en 1 Cor 9,5. Se han formulado diversas hipótesis,

72. Cfr. R. Baumann, Mitte und Norm des Christlichen. Eine Auslegung von 1 Korinther 1,1-3,4 (NTA.NF 5), Münster 1968, 51.

73. Una reducción a dos slogans, ese de Pablo y de Apolo, es criticada duramente por P. Vielhauer, Paulus und die Kephaspartei in Korinth, in: NTS 21 (1975) 347. Por el contrario, él afirma: "La enemistad hacia Pablo in Corinto parece que se reducía en tiempos de 1 Cor al partido de Pedro" (p. 351).

74. Eminentes investigadores, como E. Meyer und H. Lietzmann, abogan por la presencia de Pedro en Corinto. C.K. Barret, "Cephas" 28-39, considera posible la presencia de Pedro en Corinto. F. Pastor-Ramos, Pedro en el Corpus paulino, en: R. Aguirre Monasterio (ed.), Pedro en la Iglesia primitiva (Institución San Jerónimo 23), Estella 1991, 108, no excluye la visita, pero tampoco la afirma. Semejante opinión la encontramos también en R.E. Brown - K.P. Donfried - J. Reumann, Pedro en el Neuvo Testamento (Col. Palabra Inspirada 15), Santander 1976, 39-40. Un resumen de las distintas posiciones sobre una posible visita del apóstol a Corinto nos la ofrece $M$. Gougel, L'apôtre Pierre a-t-il joué un rôle personnel dans les crises de Grèce et de Galatie?, in: RHPhR 14 (1934) 461-500. Él no acepta la estancia de Pedro en Corinto (477s.). Cfr. G. Lüdemann, Paulus Bd. 1,157, n. 10. P. Vielhauer, "Paulus" 341-352, excluye también la actividad de Pedro en dicha ciudad por la 
aunque ninguna cuenta con apoyos textuales: a) Que fueran convertidos de Pedro cuando éste predicó en Corinto. b) Es posible que algunos de sus seguidores emigraran a Corinto procedentes de comunidades petrinas, o que estaban bajo el influjo de desconocidos judeocristianos de Jerusalén (o incluso de Antioquía), los cuales apelaban 76 al nombre de Cefas. c) Los que decían "yo soy de Cefas" pudieran ser corintios disgustados por la disputa entre las facciones que se habían agrupado alrededor de los predicadores locales, Pablo y Apolo, y apelaban a una autoridad superior de Jerusalén, es decir, al famoso Cefas. d) Con la mención de Cefas, Pablo ha querido despersonalizar el problema de la rivalidad entre él y Apolo, o mejor, entre su grupo y el grupo de Apolo ${ }^{77}$.

Expongamos brevemente, como ejemplo de la hipótesis b) la tesis defendida por C.K. Barret. Este autor quiere ver en la cuestión del procesamiento de cristianos ante tribunales paganos, en la carne ofrecida a los ídolos y en la Cena del Señor indicios para afirmar: Cefas era un judaísta moderado que quería imponer en Corinto un programa judaísta. El grupo habría adoptado una actitud nomista judeocristiana, no suficientemente extrema como para dividir a la iglesia como habría sucedido si hubieran exigido la circuncisión.

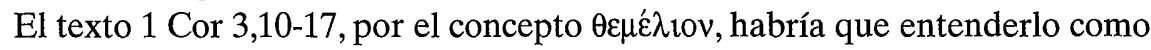
antipetrino. Tal vez el versículo 3,11 sería una antítesis contra ideas difundidas en la comunidad, una crítica a Pedro y a su pretendida supremacía (cfr. Mt 16,18). Ph. Vielhauer interpreta este versículo como un ataque a las aspiraciones petrinas al primado. Por lo tanto, la crítica paulina a las pretensiones de Pedro se corresponde perfectamente a los ataques al apostolado de Pablo por parte del partido de Pedro. Querían imponer la pretensión del primado petrino también en Corinto ${ }^{78}$. Ph. Vielhauer opina que la disensión entre los partidarios de Cefas y los de Pablo no residía en cuestiones rituales, sino sobre todo en la eclesiología.

forma como viene mencionado en 1 Cor. Véase también E. Lohse, St. Peter's Apostleship in the Judgment of St. Paul, the Apostle to the Gentiles, in: Gregorianum 72 (1991) 430; W. Reinbold, Propaganda und Mission im ältesten Christentum. Eine Untersuchung zu den Modalitäten der Ausbreitung der frühen Kirche (FRLANT 188), Göttingen 2000, 75, n. 130.

75. La afirmación de Dionysius (en Eusebius, HE II 25,8), que ambos, Pedro y Pablo, plantaron y enseñaron en Corinto, remonta a 1 Cor. Ni la literatura clementina ni 1 Petr 1,1 atribuyen a Pedro una actividad misionera en Corinto.

76. M. Goguel, "Apôtre" 493, opina: "Estos que causaron problemas en la iglesia de Corinto no fueron los apóstoles de Jerusalén, sino gente que se reclamaban a ellos. Pablo distingue netamente entre los jerosolimitanos y éstos, por lo que él no pudo haber creído que los agitadores de Corinto fueran sus delegados". Cfr. H. Merklein, 1 Kor 149.

77. G. Sellin, "Geheimnis" 74. 
Una crítica directa a Pedro presupone que éste era culpable y responsable de la existencia de su partido, es decir, Pedro mismo habría misionado en Corinto y criticado duramente a Pablo, o bien habría encargado a sus secuaces ese cometido. Contra la interpretación de $P h$.Vielhauer, hay que aducir el hecho que 1 Cor 3,11 s no se tiene que referir necesariamente a Pedro. El contexto tampoco permite esa referencia de 1 Cor 3,11 a Mt 16,18. En el texto del evangelista es el mismo Jesús quien declara a Pedro piedra, mientras que en 1 Cor 3,11 es Cristo el fundamento que el apóstol ha colocado.

Si existía una actitud polémica del partido de Pedro contra Pablo, entonces la aparición u origen de los partidos de Apolo y Pablo se explicaría como reacción a la formación del partido petrino ${ }^{79}$. Esta polémica se apoya también en argumentos literarios y de historia de las formas. De la relación entre los versículos 1 Cor 9,12 y 9,5 concluye $G$. Lüdemann ${ }^{80}$, que el término ö $\lambda \lambda$ or se refiere a misioneros judeocristianos ${ }^{81}$, quienes alegaron el ejemplo de Pedro contra Pablo, exigieron para sí el status de apóstol (se dejaban cuidar por la comunidad) y pusieron el tela de juicio la dignidad apostólica de Pablo. Este exégeta presupone en Corinto una directa misión antipaulina protagonizada por judeocristianos. Pero ya hemos indicado anteriormente que aquí no tenemos ninguna discusión con judaístas, y de haber sido ese el caso, Pablo habría arremetido como contra sus adversarios judeocristianos en Galacia y Filipos.

G. Sellin ${ }^{82}$ quiere explicar el slogan de Pedro mediante la suposición de que los partidos de Pablo y Apolo querían apelar a una autoridad tradicional para llegar a un compromiso. Pero es muy improbable que los partidarios de Pablo después del incidente de Antioquía hubieran querido tener como juez arbitrario a un "adversario" para alcanzar un compromiso. H. Merklein ve en los conflictos de Corinto no sólo problemas de integración social y culturales

78. Vgl. H.-J. Klauck, 1 Kor 21. Algunos exégetas interpretan el versículo 3,10 en relación con Mt 16,18 como una crítica paulina a la pretensión petrina (reivindicación) del primado, la cual corresponde a los ataques hacia el apóstol Pablo de parte del partido de Cefas (p.e. C.K. Barrett, P. Vielhauer, G. Lüdemann, Paulus II 121). En contra W. Schrage, 1 Kor 145. Según H. Merklein, 1 Kor 137, y G. Sellin, "Hauptprobleme" 3013s., el versículo 3,10 no se refiere a Pedro sino a Apolo. H.-J. Klauck, 1 Kor 32s.: "Gemeint wäre dann ein ortsansässiger Wortführer innerhalb der Apollos- oder Petruspartei, der sich zu Unrecht auf deren Programm beruft".

79. G. Lüdemann, Paulus II 121.

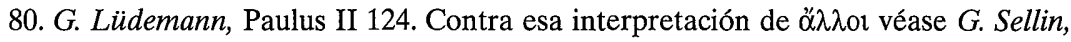
"Hauptprobleme" 3012, n. 374; S. Vidal, Cartas 194, n. 133: Apolo.

81. Ch. Wolff, 1 Kor 28, los considera también judeocristianos, aunque no aparece en la carta ninguna eclesiología petrina.

82. G. Sellin, "Hauptprobleme" 3014. 
o de formación (grupos de Pablo y Apolo), sino también étnicos y religiosos (cfr. 1 Cor 1,22-24; 9,19-23; 10,32). Según este autor habría que pensar en cristianos que exigieron la observancia de ciertas normas para la integración de judíos y gentiles, normas que habían sido asociadas al nombre de Pedro. Este partido petrino estaría compuesto por un grupo mixto de judeocristianos y pagano-cristianos, el cual se opuso contra la práctica permisiva y liberal de participar en los banquetes ofrecidos a los ídolos. Probablemente los "débiles" apelaban a Cefas y pusieron en entredicho la competencia de Pablo como apóstol en comparación con Pedro. Este estudioso considera como posible una estrecha relación entre la problemática en Corinto y en Antioquía83. Detrás de las palabras de Pedro, por tanto, no se escondían sólo judeocristianos, sino también pagano-cristianos. Por supuesto que no eran agresivos judaístas conservadores.

El hecho de que el partido petrino en 1,12 y en 3,22 venga mencionado en último lugar se aclara porque la rivalidad entre el grupo petrino y el paulino en Corinto era menor que la rivalidad existente entre los partidos de Apolo y el paulino. Para ello no hay que presuponer, como han querido ver algunos exégetas, que Pedro fue el último en llegar a Corinto, o porque él gozase de menor estima en dicha ciudad. Seguramente que el número de partidarios de este grupo petrino era insignificante, de modo que Pablo no tuvo que dirigir su atención y crítica en primer lugar contra ellos. Éstos no habrían participado en la discusión sapiencial, por lo cual encontraron menos aceptación entre los corintios ávidos de sabiduría. No constituían para Pablo en esos momentos el frente al que tenía que prestar más atención. Se podría suponer que estos misioneros habrían tenido poco éxito entre el reducido círculo de judeocristianos o posélitos, y menos aún entre los paganos.

Si se piensa que eran judaístas, entonces no estaba muy distante en el tiempo la problemática de Galacia, hecho que Pablo no quiere mencionar, pues sería como arrojar leña al fuego. Pablo no quería que se repitiera la problemática de Galacia, y después de haber descrito su relación con Apolo pasa a la de Pedro. Pablo polemizaría contra sus partidarios e indirectamente contra Pedro.

No podemos determinar quiénes eran estos hombres, dado que Pablo no menciona ningún nombre. Un directo influjo teológico por parte de Pedro

83. H. Merklein, 1 Kor 151, resumen su tesis referente al partido de Pedro: Hay que partir de la idea de que el partido de Cefas se constituyó como reacción a la lucha entre los partidos de Pablo y Apolo. La gente de Pedro era escéptica sobre la disputa de la verdadera "sabiduría" y el auténtico "logos", mientras no cumplieran en la práctica un mínimo de exigencias, mucho más importante para ellos que estériles disputas 'filosóficas'. 
sobre este grupo no se puede probar de ningún modo en el texto. Tampoco se pueden identificar con los judaístas de Galacia, porque no viene mencionado ni la exigencia de la circuncisión, ni el cumplimiento de la ley mosaica ni la observancia de un calendario cúltico. En esta carta no encontramos alusión alguna a una discusión o a un debate fundamental sobre la ley. De las escasas indicaciones paulinas, no se percibe que este grupo defendiera una forma de pensar judaísta. Por falta de información no se puede concretar con precisión la caracterización de este grupo. Seguramente constituyeron un frente antipaulino ${ }^{84}$, que ponía en tela de juicio las pretensiones de Pablo de ser apóstol, así como de su práctica misionera, como nos deja entrever 1 Cor 9,2-3.

\subsection{Dos Partidos: El partido de Apolo y el de Pablo}

De los pasajes 1,$12 ; 3,4$ s y 4,6, donde viene mencionado Apolo en relación con Pablo, se ha concluido que los conflictos en Corinto habían surgido en primera línea en torno a estos dos apóstoles. Un grupo considera a Apolo como su jefe. Pero un conflicto directo entre los dos está excluido según la actitud que muestra Pablo en 1 Cor 16,12, o al menos es la imagen que quiere transmitir Pablo a los corintios. Personalmente no se consideraban ni competidores ni enemigos.

De la lectura de la carta se obtiene la impresión que había un grupo de Corinto que mostraba una cierta actitud negativa hacia Pablo, y esperaban que no regresara, mientras eran favorables y esperaban un regreso inmediato de Apolo (1 Cor 16,12). Pablo indica que ha insistido a Apolo para que regrese a Corinto, e intenta con ello evitar un malentendido innecesario; el Apóstol afirma que él no está impidiendo esta visita. El problema no es entre Pablo y Apolo, a quien considera su cooperador (1 Cor 3,9) y hermano (1 Cor 16,12), sino entre algunos corintios y Pablo. Ésos preferían a Apolo (1 Cor 4,6). Uno se podría preguntar por qué son favorables a Apolo y reticentes a Pablo. El

84. Contra la formación de un frente petrino se expresa $M$. Karrer, Petrus im paulinischen Gemeindekreis, in: ZNW 80 (1989) 212. Este estudioso afirma que la gente de Pedro se presentaba como individuos independientes sin formar un grupo y las cuestiones de autoridad en sentido estricto no tenían ninguna importancia para ellos. "In Korinth bestand kurz eine auf ihn [Petrus] orientierte Gruppe, war zudem eher individualistisch-enthusiastisch denn judaistisch geprägt". Este estudioso no acepta la tesis de una actividad propagandista antipaulina-judaísta por parte de Pedro en el círculo de la comunidad paulina. Pedro pierde toda relevancia en los escritos del círculo paulino después de la composición de 1 Cor y Gal, cfr. T.V. Smith, Petrine Controversies in Early Christianity. Attitudes towards Peter in Christian writings of the first two centuries (WUNT II 15), Tübingen 1985. 
pasado y trasfondo de Apolo y su estilo misional nos podrían proporcionar alguna indicación para responder a esa pregunta.

De su persona conocemos poco. Pablo no ofrece a sus lectores información directa sobre el pasado de Apolo, ni indica su posición teológica. No obstante podemos concluir de la 1 Cor que Apolo tiene suficiente peso específico como líder en la comunidad de Corinto para algunos que lo consideran incluso superior a Pedro y Pablo $(1,12)$. Lucas nos trasmite alguna información más sobre Apolo, cuyo valor histórico es controvertido. Viene presentado en Hech 18,24 como un judío originario de Alejandría, hombre elocuente ${ }^{85}$ y versado en las Escrituras. De estos datos se ha deducido que es probable que en Alejandría entrara en contacto con grupos que especulaban sobre la "sabiduría", con la filosofía judeo-helenística, la interpretación alegórica de la Escrituras y hubiera aprendido retórica. A él se le atribuye la elocuencia y el fervor del espíritu (don del espíritu), distintivos también de la sabiduría corintia.

El grupo de Apolo viene mencionado en 1 Cor 1,12; 3,4; 3,22, 4,6 y siempre relacionado con el de Pablo. Esto indica que los dos grupos que apelaban a ambos apóstoles habían entrado en conflicto. No era sencillamente una cuestión de elegir favoritos entre sus maestros. La mayoría está en contra de Pablo. Según 4,3, el orgullo les ha llevado a "inflarse" contra Pablo, a juzgarlo y a ponerse a favor de "uno" (Apolo) y en contra del "otro" (Pablo) $(4,6)^{86}$. Tenemos así una crítica a Pablo. ¿Cómo ha sucedido esto si, como Pablo dice, él y Apolo están trabajando juntos?

Las disputas se originarían probablemente por el proceder crítico de un grupo concreto contra Pablo. Lo más probable es que estén poniendo en tela de juicio la autoridad paulina y modificando el evangelio hacia el helenismo. Lo que está en juego al negar ellos su autoridad no es su propia persona, sino el evangelio que él predica ${ }^{87}$. La crítica giraría en torno a la sabiduría (1 Cor 2,6-3,3) y a la artes retóricas ${ }^{88}$ (1 Cor 1,17; 2,1-5; 4,19-20). El discurso sapiencial de Apolo despertó fascinación, admiración e interés en algunos círculos en Corinto, por lo que pudo surgir una relación especial entre Apolo y este

85. La expresión d่vì $\lambda$ ó $\gamma$ loç se puede traducir como "hombre elocuente", "hombre educado" u "hombre habilidoso", cfr. D.P. Ker, "Paul" 77.

86. G. Fee, 1 Cor 193s.; W. Schrage, 1 Kor 336s. Según otra posible interpretación se podría referir a los creyentes de la comunidad, aunque no la apoya el contexto, pues trata de la relación entre Pablo y Apolo. Errónea me parece la interpretación de M.D. Goulder, $\Sigma o \phi 1 \alpha$ in 1 Corinthians, in: NTS 37 (1991) 516-534, pues identifica "uno" con el tanden "Pablo- Apolo" y "otro" con Pedro. 
círculo. Un grupo invocaba el nombre de Apolo y estaba fascinado por la hermenéutica sapiencial judeo-helenista. Esta sabiduría tenía un carácter noético e idealista, y aspiraba a obtener "el conocimiento", que venía expresado con el concepto "logos de la sabiduría". Por medio del Espíritu se obtendrían estos dones de la sofía y de la gnosis. Ellos se consideran a sí mismos pneumatikoi ${ }^{89}, \mathrm{y}$ dudan que Pablo lo fuera $(14,37)$. Están dotados espiritualmente y tienen una sabiduría especial y conocimiento superior. Por el contrario, la predicación de Pablo les parecía infantil (3,1s), y no tenía la habilidad retórica de Apolo (1 Cor 2,1-5; 2 Cor 10,10), la cual de ordinario acompañaba a la sabiduría. Esta autocomprensión les lleva a jactarse, están llenos de arrogancia $(5,6)$ y toleran en medio de ellos la inmoralidad.

Otros aspectos importantes de su teología eran influencias culturales. Así el dualismo helenístico les llevó a despreciar el mundo material, dado que se consideraban espirituales. Esto quiere decir que el cuerpo carecía de importancia $(6,13)$, tanto en este mundo como en una futura resurrección $(15,12)$. Esta concepción del cuerpo les lleva a aceptar la inmoralidad sexual o a afirmar la negación de las relaciones sexuales dentro del matrimonio $(6,12-20$; 7,1-6).

Por lo que refiere a la identificación de este grupo, algunos exégetas, que defienden la hipótesis de un único frente antipaulino en Corinto, quieren ver en ellos tendencias gnósticas a causa del dualismo, de la forma de entender la sofía (sabiduría) y en su relación con su entusiasmo (1 Cor 4,6-13), que defendían una escatología presente y realizada ${ }^{90}$. Como espirituales han experimentado el Espíritu pleno, y la glosolalia era para ellos la evidencia de que han llegado a la meta definitiva. Ellos opinan que tanto la Tradición de los Logoi como también la escatología presente en su esencia tienen su origen en la gnosis. En contra de la tesis gnosticista, hay que decir que en 1 Cor no está presente ninguno de los elementos esenciales del gnosticismo excepto el dua-

87. G. Fee, 1 Cor 13.

88. Según D.P. Ker, "Paul" 83, no sabemos el contenido de la predicación de Apolo, sin embargo podemos determinar la respuesta de los corintios. Si Apolo tenía habilidad retórica y los corintios apreciaban la retórica, no extraña que se estableciera una relación de cordialidad entre ellos.

89. Según $G$. Fee, 1 Cor 15 , el ser pneumatikos estaría relacionado con su experiencia del Espíritu, especialmente su énfasis excesivo en el don de lenguas.

90. W. Schmithals sostiene la tesis que en Alejandría dominaba no sólo un entusiasmo general, sino una gnosis con tintes mitológicos (el mito gnóstico de Cristo-hombre primitivo). Pero la existencia de tal mito no se ha podido demostrar para Corinto. H. Conzelmann, 1 Kor 30, los define como Proto-gnósticos, que defendían la gnosis en un statu nascendi. S. Arai, Die Gegner des Paulus im I. Korintherbrief und das Problem der Gnosis, in: NTS 19 (1972-73) 437: "Los enemigos de Pablo en Corinto estarían inclinados al gnosticismo, pero 
lismo en sí y ese dualismo puede explicarse por otras razones ${ }^{91}$. Sería un anacronismo pensar que tenemos categorías gnósticas de pensamiento en 1 Cor, aunque el lenguaje de 1 Cor 2,6, pudiera dar pie a pensar en ello. Otros autores, como Georgi y Friedrich, consideran a los adversarios en 1 Cor como docetistas.

El núcleo de la cuestión se refería a la valoración del discurso sapiencial, es decir, del hablar retóricamente colorido y rico en intuiciones, referentes siempre a la realidad cristiana, pero capaz de ir más allá del anuncio evangélico. Es probable que Apolo fuera considerado por sus partidarios un maestro de sabiduría y que Pablo fuera despreciado, por los suyos sin embargo defendido. En todo caso, en la iglesia de Corinto se estaba dando un proceso de culto de las personalidades religiosas de los líderes con perjuicio de la centralidad de Cristo.

Pero la diferencia entre el grupo de Pablo y el de Apolo no era solamente ideológica, sino también sociológica. Los miembros del partido de Apolo pertenecían en su mayoría a la clase instruida y mejor situada de la comunidad. Su interés por la sabiduría presupone un cierto interés filosófico. De estos datos concluye $G$. Theißen que el conflicto de los partidos refleja un conflicto interno entre distintos niveles sociales y de formación o culturales ${ }^{92}$. Los protagonistas de los partidos formarían parte de las clases pudientes (cfr. 1,26). La práctica de ir a los tribunales, el participar en los banquetes sacrificiales y el apoyo financiero de los misioneros confirma su privilegiado status social y económico.

$P$. Marshall y J.K. Chow concretan más este grupo. El interés por la retórica ${ }^{93}$ y por la sabiduría en el mundo antiguo se daba sobre todo entre las clases ricas y poderosas. No sorprende que algunos de ellos buscaran amistad con filósofos itinerantes y maestros para obtener beneficios políticos y materiales. Si a los amigos-partidarios de Apolo les interesaba la retórica, es pre-

todavía no eran gnósticos". R.A. Horsley, Gnosis in Corinth: 1 Corinthians 8:1-6, in: NTS 27 (1981) 32-51, es de la opinión, que la gnosis de Corinto era simplemente el cristianismo que había sido influido por la teología judeo-helenista de Alejandría. Apoyándose en este estudioso, S. Pétrement, God 438, pone en tela de juicio las tendencias gnósticas en Corinto. Esta autora aclara la "herejía" de Corinto mediante la predicación de Apolo, que constaba de ideas paulinas, de elementos judeo-helenistas y de su propia presentación de cristianismo. Ver al respecto B.A. Pearson, The Pneumatikos-Psychikos Terminology in 1 Corinthians. A Study in the Theology of the Corinthian Opponents of Paul and its Relation to Gnosticism (SBL.MS 12), Montana 1973.

91. Véase la crítica en R.McL. Wilson, How Gnostic Were the Corinthians, in: NTS 19 (1972-1973) 65-74.

92. G. Theißen, "Schichtung" 259; cfr. Idem, "Legitimation" 288s. 
sumible que fueran ricos y bien educados, es decir, patrones de la iglesia. El tema del trabajo y de la retribución de los misioneros (1 Cor 3,8.14; 9,1-18) es un punto de discusión: los apóstoles rivales parece que reciben por sus servicios beneficios materiales, mientras que Pablo lo hace sin recompensa (1 Cor 9,17-18), por lo que han deducido que Apolo era uno de esos "maestros" rivales y se mostraba más receptivo a las ayudas de la comunidad, en contraste con la práctica del propio Pablo ${ }^{94}$. Si Apolo recibía ayuda financiera de la iglesia, se parecería a algún amigo o cliente de los patronos ricos en la iglesia. Concluye J.K. Chow que si sus presuposiciones de la situación social de la comunidad son correctas, entonces algunos ricos y poderosos patrones de la iglesia habrían criticado y retado a Pablo porque no parecía un apóstol, dado que trabajaba él mismo para alimentarse y rechazaba las ayudas económicas de la iglesia, es decir, de los patrones. Es presumible que los lazos patróncliente tuvieran una importancia decisiva en las relaciones internas de la comunidad de Corinto, a lo que Pablo se habría opuesto para salvar su libertad de acción y no ser dependiente. Por el contrario, retores respetados y maestros (tal vez Apolo), normalmente ganaban el status y el estilo de vida de las clases sociales medias profesionales aceptando el patronazgo y la ayuda de los señores. De aquí viene la rivalidad de los patrones hacia Pablo ${ }^{95}$. Este autor confirmaría lo que ya había postulado $G$. Theißen con anterioridad: El conflicto entre los partidarios de los diferentes apóstoles es una disputa por el prestigio dentro de la comunidad, polémica sostenida por los miembros de mayor rango social ${ }^{96}$. Si los litigantes (1 Cor 6,5) provenían de los sabios y los fuertes dentro de la iglesia, es natural presuponer que estaban interesados tanto en las cosas materiales como en la sabiduría especulativa; era gente prominente.

Intenta explicar los problemas de la comunidad de Corinto por medio de las convenciones del patronazgo. Constata la presencia, influencia y actividad de algunos que actuaban como patrones de la iglesia. Así el conflicto resultaba por el rechazo de Pablo de aceptar dinero de la iglesia, lo cual constituía una violación de la convención de la amistad y el patronazgo, y era considerado como deshonrar a los patronos ricos de la comunidad. Es posible que los litigantes eran patronos poderosos que no tenían escrúpulos en ejercer su poder y sus derechos, incluso en detrimento de los débiles de la comunidad.

93. Véase D. Litfin, St. Paul's Theology.

94. Cfr. D.P. Ker, "Paul" 83.

95. J.K. Chow, Patronage 112.

96. G. Theißen, Estudios 184. 
Debían su influencia no sólo a sus riquezas, sino también a sus relaciones con gente influyente de la ciudad.

\subsection{El partido paulino}

Como todo el mundo concuerda, el núcleo de este grupo estaría formado por los primeros convertidos por Pablo en Corinto. Presumiblemente cuando Apolo y otros líderes visitaron Corinto, y cuando la iglesia creció y se expandió en la ciudad, el ethos comenzó a tambalearse. Por razones de espacio para reunirse, se formarían varios grupos, los cuales harían hincapié en aspectos sociales, litúrgicos... distintivos. Eventualmente esto puedo generar una lealtad de grupo. Algunos cristianos se consideraban como los fieles a las viejas y autorizadas tradiciones frente a las nuevas tendencias emergentes en algún grupo de Corinto o de los líderes itinerantes. Los leales a Pablo apelaban a que el Apóstol fue quien plantó $(3,6.10)$ y era padre espiritual $(4,15-17)$ de la iglesia de Corinto, por lo que defendían esas prerrogativas paulinas frente a sus enemigos. Otros grupos intentaron justificar sus tendencias en otros líderes.

Pablo, sin embargo, lamentó que hubieran utilizado su nombre como slogan para el partido $(1,13 ; 3,4-9)$. La formación de grupos no había llegado a una total división en partidos organizados aislados, pues Pablo se dirige a toda la comunidad y celebran todavía todos juntos la cena del Señor $(11,17 \mathrm{ss}$.).

\section{Respuesta de Pablo}

Los conflictos en Corinto eran el resultado del debate sobre a quién había que consultar las cuestiones que tenían. Algunos sugerían a Pedro/Cefas pues era el más destacado de los apóstoles, mientras que las credenciales de Pablo eran más cuestionables. Otros habrían votado por Apolo por ser un maestro sabio e inteligente. Muchos habrían opinado que no necesitaban consultar a nadie, pues como gente llena del espíritu eran maduros para decidir por sí mismos. Dado que la carta fue enviada a Pablo, esos como Estéfanas, quienes pensaban que Pablo era la mejor elección, habrían ganado la discusión. Pablo estaba preocupado que esta disputas pudiera evolucionar en divisiones reales de la iglesia si sus recomendaciones eran recibidas entusiastamente por un grupo y rechazado por otro.

Según Dahl97 Pablo escribió 1 Cor entre otras razones para restablecer su autoridad como apóstol y padre espiritual de la iglesia de Corinto. 
Mientras Fiorenza coincide con Dahl en considerar que 1 Cor busca establecer la autoridad de Pablo, puntualiza que 1 Cor no intenta restablecer sino establecer a Pablo como la única autoridad, es decir, como el único fundador de la iglesia de Corinto ${ }^{98}$. En una situación de interpretaciones y prácticas contrapuestas de lo que significaba realizar la vida nueva en Cristo, la comunidad de Corinto decidió escribir a diferentes misioneros. Entiende 1 Cor como un discurso deliberativo en el que Pablo apela a esos que como él eran de un status educacional y social alto.

Pablo intenta imponer su autoridad en la Iglesia. La cuestión es cómo y con qué proposito era ejercida esa autoridad. Si esa autoridad fue ejercida para expulsar al inmoral de la iglesia y desanimar a los idólatras de comer en los templos de los ídolos, si estos que lo hacían eran ricos y poderosos patrones en la iglesia, entonces la autoridad de Pablo era usada para desafiar y criticar al fuerte de su falta de cuidado para con los otros. Así se explica que el apóstol subraye el ser amigos y respetar el puesto del débil dentro de la iglesia. Pablo ofrecía un modelo alternativo a las relaciones opresivas de patróncliente, las cuales constituían un sistema vertical y desigual. Por tanto, la propuesta de Pablo era un sistema con implicaciones subversivas ${ }^{99}$.

Pablo intenta persuadir a los corintios que estiman más a Apolo que a él mismo para revisar sus juicios y valoraciones. Él no usa un ataque directo y claro, pues eso hubiera empeorado la situación en una iglesia ya dividida. Más bien invita a los corintios a considerar a Apolo y a él mismo uno al lado del otro. Entonces dentro de la comparación de las contribuciones de cada uno, usa un lenguaje e imágenes destinadas para realzar su persona en sus estimas, mientras dice poco sobre Apolo.

Como conclusión hay que repetir que no es posible identificar con exactitud a los adversarios de Pablo en Corinto, pero algunos rasgos peculiares que Pablo les atribuye, ya se han puesto de manifiesto en este artículo. Una cosa es clara: no se pueden identificar con los oponentes judaístas a los que Pablo tuvo que hacer frente en Galacia y Filipos.

D. Álvarez Cineira Estudio Teológico Agustiniano Valladolid

97. N.A. Dahl, "Paul" 321.

98. E.Sch. Fiorenza, "Situation" 397.

99. J.K. Chow, Patronage 187. 